Article

\title{
Application of Improved Particle Swarm Optimization for Navigation of Unmanned Surface Vehicles
}

\author{
Junfeng Xin ${ }^{1}$, Shixin Li ${ }^{1}$, Jinlu Sheng ${ }^{2}$, Yongbo Zhang ${ }^{3, *}$ and Ying Cui ${ }^{1, *(\mathbb{D}}$ \\ 1 College of Electromechanical Engineering, Qingdao University of Science and Technology, \\ Qingdao 266061, China \\ 2 Transport College, Chongqing Jiaotong University, Chongqing 400074, China \\ 3 Qingdao National Marine Science Research Center, Qingdao 266071, China \\ * Correspondence: zhangyongbo654@163.com (Y.Z.); cuiying@qust.edu.cn (Y.C.)
}

Received: 14 June 2019; Accepted: 11 July 2019; Published: 13 July 2019

\begin{abstract}
Multi-sensor fusion for unmanned surface vehicles (USVs) is an important issue for autonomous navigation of USVs. In this paper, an improved particle swarm optimization (PSO) is proposed for real-time autonomous navigation of a USV in real maritime environment. To overcome the conventional PSO's inherent shortcomings, such as easy occurrence of premature convergence and human experience-determined parameters, and to enhance the precision and algorithm robustness of the solution, this work proposes three optimization strategies: linearly descending inertia weight, adaptively controlled acceleration coefficients, and random grouping inversion. Their respective or combinational effects on the effectiveness of path planning are investigated by Monte Carlo simulations for five TSPLIB instances and application tests for the navigation of a self-developed unmanned surface vehicle on the basis of multi-sensor data. Comparative results show that the adaptively controlled acceleration coefficients play a substantial role in reducing the path length and the linearly descending inertia weight help improve the algorithm robustness. Meanwhile, the random grouping inversion optimizes the capacity of local search and maintains the population diversity by stochastically dividing the single swarm into several subgroups. Moreover, the PSO combined with all three strategies shows the best performance with the shortest trajectory and the superior robustness, although retaining solution precision and avoiding being trapped in local optima require more time consumption. The experimental results of our USV demonstrate the effectiveness and efficiency of the proposed method for real-time navigation based on multi-sensor fusion.
\end{abstract}

Keywords: travelling salesman problem; particle swarm optimization; parameter setting; random grouping inversion; unmanned surface vehicle; multi-sensor data

\section{Introduction}

It is well known that multi-sensor fusion is an important issue for autonomous navigation of unmanned vehicles, especially when operating in real environments with unanticipated changes. With the aid of various types of sensors, such as temperature and humidity sensors, collision sensors, flow velocity and flow rate sensors, and displacement sensor, unmanned vehicles have been effectively applied to the fields of sounding survey [1], environment monitoring [2], underwater acoustics [3], marine rescue [4], target tracking [5], and water monitoring [6]. In these cases, all of the sensory information from multiple sensors is combined and effectively utilized to generate desirable trajectories for unmanned vehicles to follow, which is always formulated as a travelling salesman problem (TSP).

The TSP was proved to be a typical non-deterministically polynomially hard combination optimization problem in 1979 [7]. Its goal is to design the shortest route for a traveler to visit each city 
without repetition and ultimately return to the departure city. With the search-space tending to infinity and complexity, traditional exact algorithms, such as the enumeration method, fail to approach an exact solution within a reasonable computation time. Hence, novel algorithms with the capability of self-organization and self-adaption need to be developed to discover an adequate solution, sacrificing optimality, accuracy, and completeness for running speed. Inspired by natural evolution models and adaptive population evolution, collective intelligence methods, including genetic algorithm [8], particle swam optimization (PSO) [9], ant colony optimization (ACO) [10], artificial fish swarm algorithm [11], and artificial bee colony algorithm [12], have entered into a stage of rapid development for the TSP.

Particle swarm optimization, proposed by Eberhart and Kennedy in 1995, is an evolutionary metaheuristic technique [13]. It solves the optimization problem by having a population of candidate solutions, called particles, and moving these particles around in multi-dimensional search-space with a certain velocity. With a fitness function to assess each solution, the movements of all of the particles are dynamically guided by their own experience, as well as the entire swarm's experience. Finally, it is expected that the swarm will move toward the most satisfactory solution. Due to advantages of fast convergence speed, simple parameter settings, and easy implementation, the PSO algorithm has been widely used in various fields, including functions optimization [14], training of neutral networks [15], and fuzzy system control [16].

Additionally, in order to improve the performance of PSO in solving the discrete-space-based TSP, valuable research has been conducted in recent times on the hybridization of heuristic methods. B. Shuang et al. proposed a hybrid algorithm that combined the respective advantages of PSO and ACO. The search mechanism of PSO was effectively utilized in which the particle's experience helped to expand the search space, while the swarm experience pushed the global convergence [17]. X. Zhang et al. improved PSO by using a priority coding method to code the solution, dynamically setting the velocity range to remove the side effect due to the discrete search-space, and introducing the k-centers method to avoid the local optimum. The improved algorithm performed well in reserving the swarm diversity [18]. A hybrid fuzzy learning algorithm was proposed by H. M. Feng et al. in a large-scale search-space. The adaptive fuzzy C-mean algorithm was first used to divide the large-scale cities into subsets, following by the transform-based particle swarm optimization and the simulated annealing method acquiring the local optimal solution. Then the complete optimal route was rebuilt by the powerful MAX-MIN merging algorithm [19]. In the work by M. Mahi et al., the authors introduced the PSO into the ACO to help to optimize the city selection parameters, and the 3-opt algorithm was used for the purpose of jumping out of the local optimum [20]. In addition, the combination of PSO with genetic algorithm by W. Deng et al. [21], and the method combining PSO with artificial fish swarm algorithm [22] also show admirable improvement.

It is well known that the PSO performance depends heavily on the proper balance between exploration, namely searching a broader space, and exploitation, namely, moving to the local optimum. It contends that tuning the PSO parameters has a significant impact on the optimization performance. Hence, choosing proper parameters to improve the algorithm effectiveness has been a hot spot for many works. In the work by Y. Zhang et al., the raw fitness value was adjusted by the power-rank scaling method, the acceleration coefficients and the inertia weight were changed with iteration, and the random numbers were modified to be generated by a chaotic operator. Simulation results showed that the novel method succeeded elite genetic algorithms with migration, simulated algorithm, chaotic artificial bee colony, and PSO in both success rate and time cost [23]. To solve the vehicle routing problem with time windows, a variant of PSO with three adaptive strategies was used, in which all parameters started with random values, but gradually tended to be applicable during iterations based on some limitations [24]. K. R. Harrison et al. analyzed the results of PSO using 3036 configurations of control parameters for 22 benchmark problems and found the time-dependence of optimal values. Meanwhile, the optimal range of acceleration coefficients and inertia weight were recommended [25].

Moreover, with the fast development of intelligent algorithms and autonomous navigation technology, PSO has also been successfully applied to the vehicle path planning problem. R. J. Kenefic 
combined a heading constraint heuristic with PSO to solve the turn rate limited TSP for an unmanned aerial vehicle. Permutations of the tour vertices' orders were considered to eliminate the self-crossing phenomenon in the planned path. Results revealed that PSO performed better than a standard algorithm in MATLAB because of the discontinuous and multimodal nature of the objective function [26]. To plan the shortest and smoothest route for the robot, a novel algorithm was presented with the PSO component used as a global planner and the modified probabilistic road map method used as a local planner. Results showed that this PSO-based algorithm was advantageous in runtime and path length [27]. M. D. Phung et al. improved the PSO by integrating deterministic initialization, random mutation, and edge exchange. Experimental tests with real-world datasets from unmanned aerial vehicle inspection showed the proposed algorithm could enhance the performance in both computing time and travelling cost [28]. To plan a multi-objective optimization path for an autonomous underwater vehicle in dynamic environments, the PSO was used to find suitable temporary waypoints, combined with the waypoint guidance to generate an optimal path [29].

In order to avoid premature convergence, route self-crossing, and to enhance the robustness, this work proposes three improved algorithms on the basis of the PSO method by combining one or two optimization strategies as follows: linearly descending inertia weight, adaptively controlled acceleration coefficients, and random grouping inversion. First, a hundred Monte Carlo simulations are conducted for five TSPLIB instances in order to compare the effectiveness of each improved algorithm in terms of route length, computing efficiency and algorithm robustness. Furthermore, improved PSO algorithms are applied to the navigation, guidance and control system (NGC) of a self-developed USV with multi-sensor data in a real sea environment.

The main contributions of this work are as follows: (1) The important parameters, including the acceleration coefficients and inertia weight, are adjusted iteratively, with the aim of effectively reducing the path length and enhancing the robustness; (2) The strategy of random grouping inversion maintains the swarm diversity and accelerates the global convergence, which can avoid premature convergence and retain solution precision; (3) Path planning for a USV is conducted by combining the conventional PSO with the three optimization strategies, which generates feasible routes with satisfactory length and no self-crossing.

The rest of the paper is structured as follows. PSO algorithms with different optimization strategies are introduced concisely in Section 2. Results and discussions of Monte Carlo simulations and applications to a USV are presented in Section 3. Additionally, conclusions and future research directions are drawn in Section 4.

\section{Proposed Algorithms}

\subsection{Particle Swarm Optimization}

As mentioned in Section 1, the conventional PSO is a population-based stochastic optimization method. At the beginning of the evolutionary process, the PSO method generates $N$ candidate solutions (namely $N$ particles) randomly within an $S$-dimensional search space. For the $i$-th particle, its position can be represented by a vector $X_{i}=\left(x_{i 1}, x_{i 2}, \ldots, x_{i S}\right)^{T}$. Meanwhile, its velocity can be defined by a vector $V_{i}=\left(v_{i 1}, v_{i 2}, \ldots, v_{i S}\right)^{T}$. A fitness function is used to evaluate the quality of each solution. For the TSP and path planning problem in this work, the fitness function is defined as $1 / D(D$ stands for the route length). For every iteration, all the particles depend on two kinds of experience for guiding their movement: the best position $\left(P_{i s}\right)$ an individual has known so far, and the best position $\left(P_{g s}\right)$ the entire swarm has known so far. Correspondingly, the velocity and position of each particle are updated following Equations (1) and (2) [30].

$$
\begin{gathered}
v_{i s}^{m+1}=w v_{i s}^{m}+c_{1} r_{1}^{m}\left(P_{i s}^{m}-x_{i s}^{m}\right)+c_{2} r_{2}^{m}\left(P_{g s}^{m}-x_{i s}^{m}\right), \\
x_{i s}^{m+1}=x_{i s}^{m}+v_{i s}^{m+1},
\end{gathered}
$$


where $m$ and $s$ stand for the current number of iterations and the $s$-th dimension, respectively. $r_{1}$ and $r_{2}$ are random and iteratively updated numbers uniformly distributed between 0 and $1 . c_{1}, c_{2}$, and $w$ are PSO control parameters called personal cognition coefficient, social cognition coefficient, and inertia weight, respectively.

It should be noted that there are three terms of velocity on the right side of Equation (1). The first term $w v_{i s}^{m}$ is the inertia component, which makes the particle move in its original direction of last iteration. The inertia weight $w$, first proposed by Y. Shi and R. C. Eberhart in 1998, affects the capability of global search and algorithm convergence, and it is typically set between 0.8 and 1.2 [30]. The second item $c_{1} r_{1}^{m}\left(P_{i s}^{m}-x_{i s}^{m}\right)$ is called the personal cognition component, which causes the particle to move according to its memory of individual best-known position. Meanwhile, the third item $c_{2} r_{2}^{m}\left(P_{g_{s}}^{m}-x_{i s}^{m}\right)$ is the social cognition component, which will guide the particle to move towards the swarm's best known position based on communication with other particles. The acceleration coefficients $c_{1}$ and $c_{2}$ play an important role in balancing the effects of personal cognition and social cognition on guiding the particle towards the target optimal solution. The values of $c_{1}$ and $c_{2}$ are usually suggested to be 2. In addition, it is reported that the stochastic characteristics of $r_{1}$ and $r_{2}$ can weaken the effects of the individual best known position and the swarm best known position on the velocity update. The diversity of population could be maintained, and the phenomenon of premature convergence could be avoided to some degree [31].

Figure 1 shows a schematic diagram of position change of a particle for two successive iterations. The algorithm procedure will be terminated when the maximum number of iterations $(M)$ or a minimum error threshold is achieved. The pseudo code of conventional PSO is presented in Algorithm 1.


Figure 1. Shematic diagram of a particle's position update in PSO. 


\subsection{Linearly Descending Inertia Weight}

Note that the inertia weight $w$ reflects the effect of historical velocity on current velocity for each particle. It could balance the capacities of local and global searching. When $w=0$, it could be found based on Equation (1) that the particle velocity only depends on its current cognition of the personal best-known position $\left(P_{i s}\right)$ and the swarm's best known position $\left(P_{g s}\right)$. If one particle is in its current $P_{g s}$, it will remain stationary, while others will fly at a weighted speed of $P_{i s}$ and $P_{g s}$. Given this circumstance, the entire swarm will be pulled towards the current $P_{g s}$ and converge to the local optimum. On the contrary, with the aid of the inertia component, all the particles have a tendency to explore a larger space. Hence, when faced with various optimization problems such as functions optimization, training of neutral network, and Fuzzy system control, it is necessary to adjust the value of $w$ to balance the algorithm capability of local and global searching.

In addition, the inertia weight $w$ also affects the global search behavior, especially the convergence behavior. Generally, a lower value of $w$ would help speed up the convergence of global optimum, while a larger value of $w$ would contribute to the exploration of the entire search space. To obtain a better global search capability during early iterations, and enhance the local exploitation during later iterations to avoid being trapped into local optimum, the inertia weight $w$ is adjusted dynamically with the form of linearly descending over the iterations according to Equation (3).

$$
w=w_{\max }-m \times\left(w_{\max }-w_{\min }\right) / M
$$

where $w_{\max }$ and $w_{\min }$ represent the maximum and minimum value of inertia weight $w$, respectively.

\subsection{Adaptively Controlled Acceleration Coefficients}

The acceleration coefficients $c_{1}$ and $c_{2}$ reflect the information exchange among particles, and determine the distance a particle will move towards target solution under the guidance of personal cognition and social cognition in a single iteration. Small values of acceleration coefficients would make the particle wander far from the target region, while large values of acceleration coefficients would urge the particle to move quickly towards the target region but ultimately deviate from this region. When $c_{1}$ and $c_{2}$ are both equal to zero, the particle will fly at its current velocity until it hits the border of the search space. As a result, the satisfactory solution is hard to find within the restricted search space. If $c_{1}$ is zero, the particle will lose cognitive function. Although the search space could be enlarged by taking into account the particle interactions, it is more likely to be trapped in the local optimum when faced with a complex optimization problem. In addition, when $c_{2}$ is zero, no information exchanges exist in the swarm; each particle will work independently. It is almost impossible to find the optimal solution.

As mentioned in Section 2.1, the values of $c_{1}$ and $c_{2}$ keep constant during the whole evolutionary procedure for the conventional PSO. However, the fixed settings have inherent limitations: large values make each particle rapidly converge towards the local optimum, while low values cause each particle to wander far from target regions. Hence, a concept of iteratively linearly changing acceleration coefficients was employed by A. Ratnaweera et al. [32], Y. Zhang et al. [23], and Z. Yan et al. [29]. A relatively larger $c_{1}$ and a relatively lower $c_{2}$ were used during the early stage of iterations. With the increasing iterations, the value of $c_{1}$ was linearly reduced, while the value of $c_{2}$ was linearly increased, as formulated by Equations (4) and (5). It was reported that the linear-changing acceleration coefficients could help to reduce the probability of premature convergence during early iterations, and also enhance the convergence performance during later iterations.

$$
\begin{aligned}
& c_{1}=\left(c_{1 \min }-c_{1 \max }\right) \frac{m}{M}+c_{1 \max }, \\
& c_{2}=\left(c_{2 \max }-c_{2 \min }\right) \frac{m}{M}+c_{2 \min },
\end{aligned}
$$


where the subscripts max and min stand for the maximum and minimum values of acceleration coefficients $c_{1}$ and $c_{2}$.

However, it is thought that the effects of acceleration coefficients on algorithm convergence are restricted when their values are changing linearly during the whole evolutionary procedure. For instance, a larger influence of social information is of great significance in later stage of algorithm to improve the searching efficiency, which could not be realized timely by the simple linear variations of acceleration coefficients. Consequently, an evaluation parameter $(K)$ is introduced in this work according to the degree of swarm convergence. Its value is defined as the radio of the number of successfully converged particles (called advantageous particles) in a single iteration to the initial swarm size, as represented in Equation (6). Then the evaluation parameter $(K)$ is employed to adaptively control the changing rate of acceleration coefficients by using Equations (7) and (8).

$$
\begin{gathered}
K=P / N, \\
c_{1}=\left(c_{1 \text { max }}-c_{1 \text { min }}\right) K+c_{1 \text { min }}, \\
c_{2}=\left(c_{2 \text { max }}-c_{2 \text { min }}\right) K+c_{2 \text { min }}
\end{gathered}
$$

where $P$ stands for the number of particles that could successfully converge in a single iteration. The strategy of adaptively controlled acceleration coefficients associates the values of acceleration coefficients with the optimization status by use of the evaluation parameter $(K)$. With the increase of iterations, the number of advantageous particles in a swarm is increasing; this will enlarge the influence of advantageous particles on the entire swarm. Hence, it is supposed that excellent solutions would be protected as much as possible to help avoid local optima.

\subsection{Random Grouping Inversion}

It should be noted that the CPSO uses a single swarm consisting of all the particles for evolution. Hence, it is likely to result in a phenomenon in which all the particles cluster around a certain position and stop exploring the other area of the search-space. To avoid the easy occurrence of premature convergence, the concept of random grouping inversion is proposed and added before the update of $P_{i s}$ and $P_{g s}$ during every iteration. The single swarm is divided into several subgroups, in which independent evolution is in process. As a result, the diversity of the swarm can be strengthened and the global convergence for the entire swarm is accelerated.

As to the number of particles in a subgroup, preliminary research indicated that a larger number would decrease the inherent capability of merit-based selection, while a lower number would weaken the role of grouping mechanism. Finally, the number was set as four; in other words, four particles were randomly sorted to form a subgroup.

On the basis of the random grouping strategy, a further operation is proposed, simulating the inversion operation during the process of biologic evolution. After evaluating the fitness of each particle, all four particles clustered around the local optimum discovered by each subgroup. Then the inversion was carried out to generate new particles and replace two original particles of the subgroup, in which the TSP tour orders for two randomly selected inversion points were inversed.

Indeed, the strategy of random grouping inversion is based on Darwin's theory of evolution: internal competition of population and uncertain mutation. In theory, the internal competition of the population is a process of merit-based selection, namely, only the fittest one survives. The inversion is a type of uncertain mutation which could help to maintain the swarm diversity. Ultimately, the pool of swarm particles reserves not only the fittest individual of each subgroup, but also the inversion-based variant. Hence, it is supposed that this strategy would help to enhance the population diversity and improve the effectiveness of swarm optimization. The pseudo code of random grouping inversion is shown in Algorithm 2. 


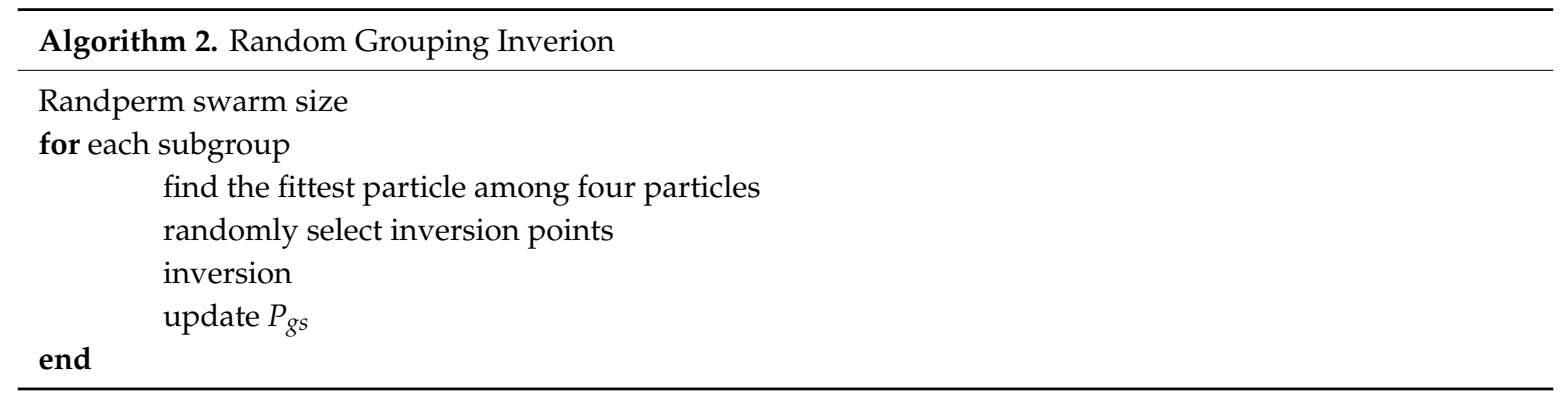

\section{Simulations and Experimental Results}

\subsection{Monte Carlo Simulations}

Three algorithms with progressively improved strategies are proposed based on the conventional particle swarm optimization (CPSO): the algorithm with adaptively controlled acceleration coefficients (APSO), the algorithm with both adaptively controlled acceleration coefficients and linearly descending inertia weight (AWPSO), and the algorithm combining the advantages of adaptively controlled acceleration coefficients, linearly descending inertia weight, and random grouping inversion (AWIPSO). To eliminate the stochastic property of PSO in MATLAB operation environment, this section employs Monte Carlo simulations to compare the performance of each algorithm for TSP from three points of view: the number of planned points, the swarm size, and the computing efficiency. All the simulations are performed on the same computer (Intel (R) Core (TM) i7-7700HQ CPU @ 2.80 GHz) with 8.0 GB memory so as to avoid the effects of computer models on the running capacity of algorithms. In addition, all the sample instances are taken from TSPLIB (Website: https://wwwproxy.iwr.uniheidelberg.de/groups/comopt/software/TSPLIB95/tsp/\#opennewwindow).

\subsubsection{Comparative Study with Different Numbers of Planned Points}

Five considered instances from TSPLIB are burma14, ulysses22, eil51, eil76, and rat99. Correspondingly, the numbers of planned points $(Q)$ are 14, 22, 51, 76, and 99, and the maximum numbers of iterations $(M)$ are set as $100,200,1600,2000$, and 2000 , respectively. The swarm size $(R)$ is set as 500 for each algorithm. For the CPSO, acceleration coefficients $c_{1}$ and $c_{2}$ are constant at a value of 2 , and $w$ is also unchanged with the value of 0.9 . For the improved algorithms, the varying range of the personal cognition coefficient $c_{1}$ is set as $0.9-1.2$, and the social cognition coefficient $c_{2}$ varies from 0.2 to 1.0 during evolutionary procedure. As to the linearly descending inertia weight $w$, the value is changing from 0.9 to 0.4 . Detailed information of parameter settings for each algorithm is listed in Table 1.

Table 1. Parameter settings for each algorithm.

\begin{tabular}{|c|c|c|}
\hline Algorithm & Parameter & Setting \\
\hline CPSO & $\begin{array}{l}\text { personal cognition coefficient } c_{1} \\
\text { social cognition coefficient } c_{2} \\
\text { inertia weight } w\end{array}$ & $\begin{array}{c}\text { constant, } 2 \\
\text { constant, } 2 \\
\text { constant, } 0.9\end{array}$ \\
\hline APSO & $\begin{array}{l}\text { personal cognition coefficient } c_{1} \\
\text { social cognition coefficient } c_{2} \\
\text { inertia weight } w\end{array}$ & $\begin{array}{l}\text { adaptively controlled by Equation (7), 0.9-1.2 } \\
\text { adaptively controlled by Equation (8), 0.2-1.0 } \\
\text { constant, } 0.9\end{array}$ \\
\hline AWPSO & $\begin{array}{l}\text { personal cognition coefficient } c_{1} \\
\text { social cognition coefficient } c_{2} \\
\text { inertia weight } w\end{array}$ & $\begin{array}{l}\text { adaptively controlled by Equation (7), } 0.9-1.2 \\
\text { adaptively controlled by Equation (8), } 0.2-1.0 \\
\text { linearly descending by Equation (3), 0.9-0.4 }\end{array}$ \\
\hline AWIPSO & $\begin{array}{l}\text { personal cognition coefficient } c_{1} \\
\text { social cognition coefficient } c_{2} \\
\text { inertia weight } w\end{array}$ & $\begin{array}{l}\text { adaptively controlled by Equation (7), 0.9-1.2 } \\
\text { adaptively controlled by Equation (8), 0.2-1.0 } \\
\text { linearly descending by Equation (3), 0.9-0.4 }\end{array}$ \\
\hline
\end{tabular}


Monte Carlo simulations are conducted one hundred times to obtain the data set of optimal path distance $(D)$ with four algorithms for each TSP instance. The comparative results are presented in box-and-whisker plots (see Figure 2). The legend and explanation of the box-and-whisker plots refer to the work by M. E. Spear [33]. In every box plot, a range bar represents the interquartile range of the data set, which indicates the degree of data dispersion and the algorithm robustness to some extent. The median value and the average value are identified with a red line and a plus symbol in the bar. Meanwhile, the whiskers are drawn extending on both sides of the bar, with the ends standing for the best and worst values, respectively. Furthermore, Table 2 lists the detailed statistics of the data set for each algorithm and each number of planned points, including the known optimal solution of TSPLIB, the worst, the best and the average values of optimal path distance. Additionally, the standard deviation is calculated to show how far the set of data is spread out from the average value, and it stands for the robustness of the algorithm.

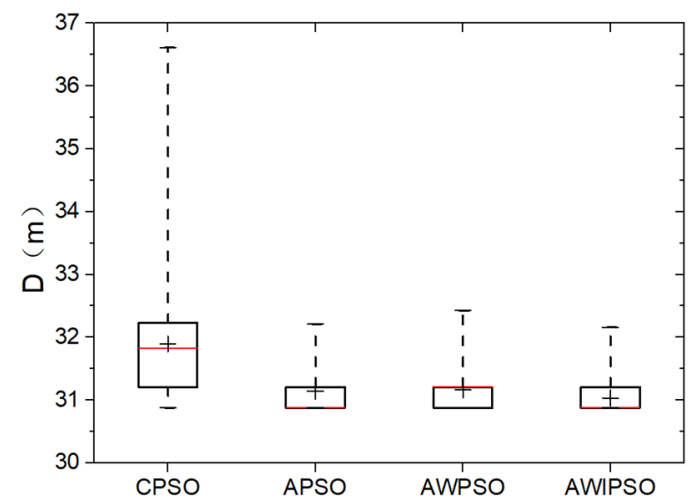

(a)

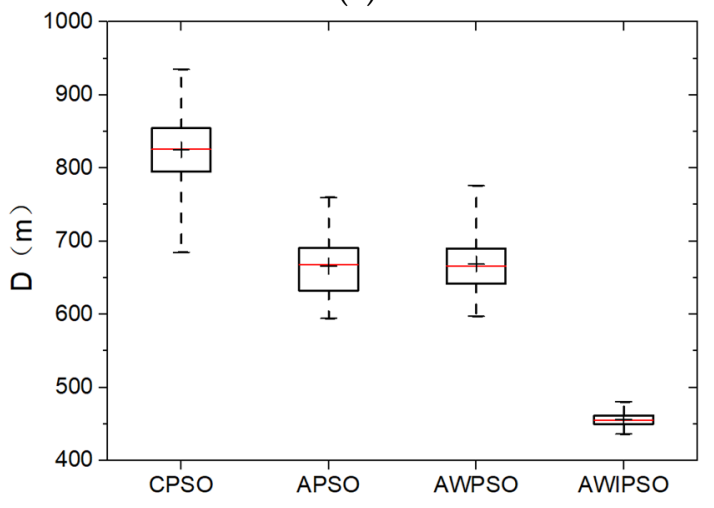

(c)

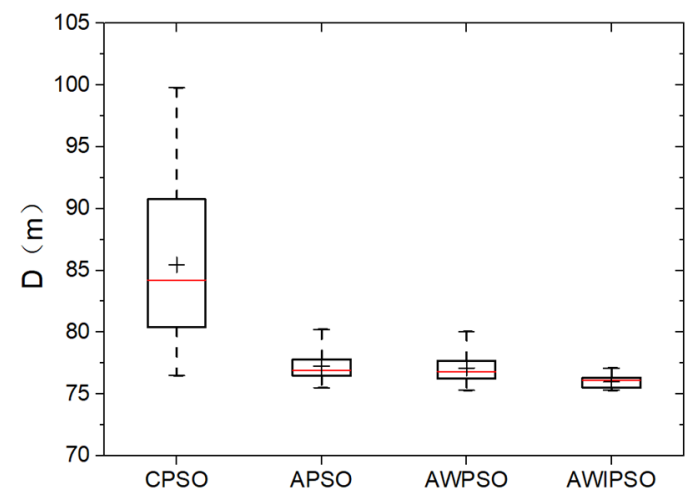

(b)

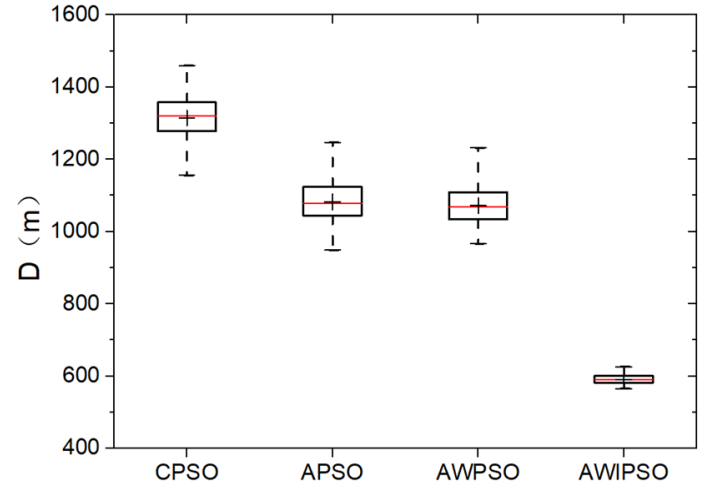

(d)

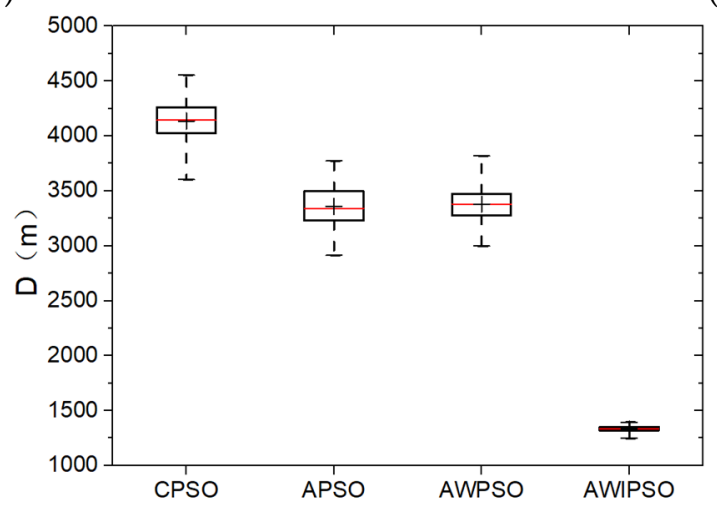

(e)

Figure 2. Solution distribution of each algorithm with five numbers of planned points: (a) $Q=14$; (b) $Q=22 ;$ (c) $Q=51$; (d) $Q=76$; (e) $Q=99$. 
Table 2. Statistical results of optimal path distance in 100 runs with five numbers of planned points.

\begin{tabular}{|c|c|c|c|c|c|c|}
\hline$Q$ & Known Optimal Solution & Algorithm & Worst (m) & Best (m) & Mean (m) & Std. Dev. (m) \\
\hline \multirow{4}{*}{14} & \multirow{4}{*}{$30.88 \mathrm{~m}$} & CPSO & 36.61 & 30.88 & 31.90 & 1.00 \\
\hline & & APSO & 32.21 & 30.88 & 31.14 & 0.36 \\
\hline & & AWPSO & 32.42 & 30.88 & 31.16 & 0.38 \\
\hline & & AWIPSO & 32.15 & 30.88 & 31.03 & 0.29 \\
\hline \multirow{4}{*}{22} & \multirow{4}{*}{$74 \mathrm{~m}$} & CPSO & 99.78 & 76.49 & 85.45 & 6.22 \\
\hline & & APSO & 80.22 & 75.50 & 77.26 & 1.13 \\
\hline & & AWPSO & 80.05 & 75.30 & 77.11 & 1.10 \\
\hline & & AWIPSO & 77.10 & 75.30 & 75.97 & 0.46 \\
\hline \multirow{4}{*}{51} & \multirow{4}{*}{$426 \mathrm{~m}$} & CPSO & 935.06 & 684.73 & 825.02 & 45.67 \\
\hline & & APSO & 759.91 & 594.27 & 665.87 & 38.96 \\
\hline & & AWPSO & 775.86 & 597.08 & 668.68 & 38.72 \\
\hline & & AWIPSO & 480.14 & 436.06 & 455.91 & 9.37 \\
\hline \multirow{4}{*}{76} & \multirow{4}{*}{$538 \mathrm{~m}$} & CPSO & 1459.78 & 1156.23 & 1315.03 & 62.90 \\
\hline & & APSO & 1247.22 & 948.52 & 1082.12 & 58.75 \\
\hline & & AWPSO & 1231.88 & 966.33 & 1071.70 & 52.48 \\
\hline & & AWIPSO & 625.39 & 564.86 & 590.11 & 12.40 \\
\hline \multirow{4}{*}{99} & \multirow{4}{*}{$1211 \mathrm{~m}$} & CPSO & 4555.13 & 3602.25 & 4136.63 & 194.64 \\
\hline & & APSO & 3772.27 & 2912.69 & 3359.80 & 178.09 \\
\hline & & AWPSO & 3819.77 & 2998.28 & 3379.08 & 173.14 \\
\hline & & AWIPSO & 1394.07 & 1248.12 & 1332.97 & 27.62 \\
\hline
\end{tabular}

Std. Dev. is the abbreviation for standard deviation.

In the instance of burma14 in Figure 2a, it is observed that the proposed optimization strategies help reduce the average values of $D$, and make the data set cluster more closely. However, a minor difference less than $0.4 \%$ is found in terms of path distance and algorithm robustness for the three improved algorithms.

When the number of planned points $(Q)$ increases (see Figure $2 b-e$ ), the respective advantages of the adaptively controlled acceleration coefficients, the linearly descending inertia weight, and the random grouping inversion emerge gradually. For $Q=76$ in Figure 2d, the strategy of adaptively controlled acceleration coefficients plays a substantial role in reducing the path length by approximate $17.7 \%$ when comparing the APSO with CPSO. Meanwhile, the linearly descending inertial weight mainly affects the degree of data dispersion. The AWPSO has a standard deviation of $52.48 \mathrm{~m}$, which is $10.7 \%$ lower than the APSO. By contrast, the AWIPSO is superior, with the shortest average path distance of $590.1 \mathrm{~m}$ and the lowest standard deviation of $12.4 \mathrm{~m}$. It can be concluded that the strategy of random grouping inversion has considerable effects on both reducing the path length and improving the algorithm robustness. In addition, the best value of AWIPSO is $1248 \mathrm{~m}$ for $Q=99$, which is only $3 \%$ larger than the known optimal solution of TSPLIB.

\subsubsection{Comparative Study with Different Swarm Sizes}

In this section, the TSP instance of eil51 with 51 planned points is selected as the working condition. Five swarm sizes $(R)$ of 300, 400, 500, 600, and 700 are considered. Furthermore, the maximum number of iterations $(M)$ for each algorithm is set as 500 . The other parameter settings of each algorithm, such as $c_{1}, c_{2}$, and $w$, are the same as those in Section 3.1.1.

The Monte Carlo simulations of one hundred times are conducted for each algorithm and each swarm size. Comparative results are shown in the form of five box-and-whisker plots in Figure 3. Detailed statistics of optimal path distance, including the four-number summary of data sets, are listed in Table 3.

When the swarm size is 300, as shown in Figure 3a, the respective advantages of the three optimization strategies could be concluded similarly as in Figure 2. The adaptively controlled 
acceleration coefficients contribute to shortening the path distance. The linearly descending inertia weight has a certain effect on reducing the degree of data dispersion by $2.1 \%$ when comparing the AWPSO with APSO. The AWIPSO performs best with an average optimal path length of $457.0 \mathrm{~m}$ and a standard deviation of $9.9 \mathrm{~m}$. Compared with the AWPSO, the effects of random grouping inversion are clear in both shortening the path distance and improving the algorithm robustness. In addition, the median value is almost coincided with the mean value in each bar; this means all the algorithms could produce uniformly distributed data for the condition of eil51.

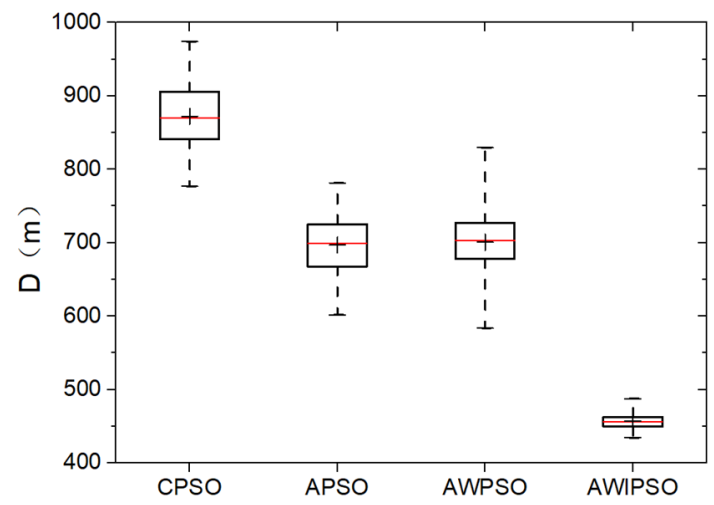

(a)

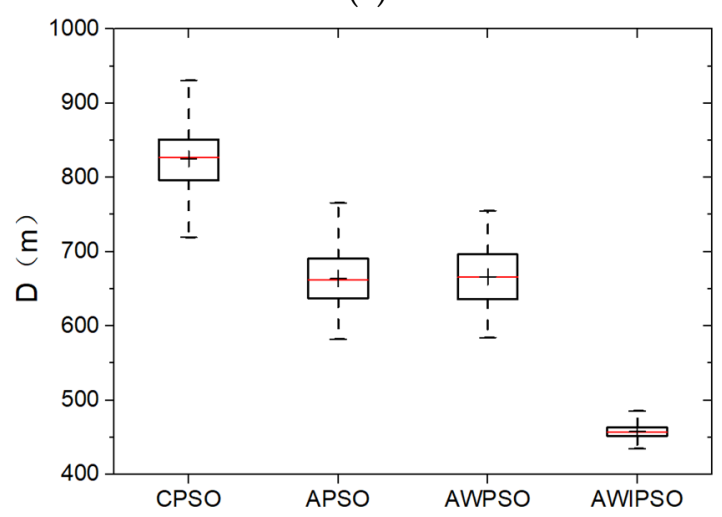

(c)

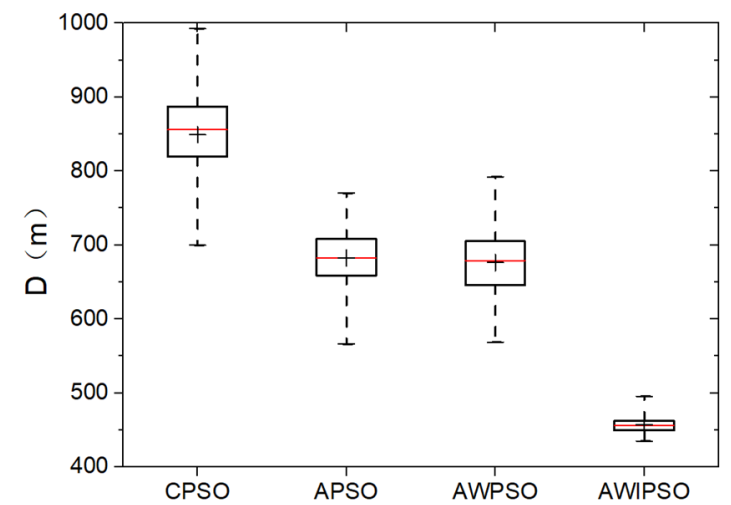

(b)

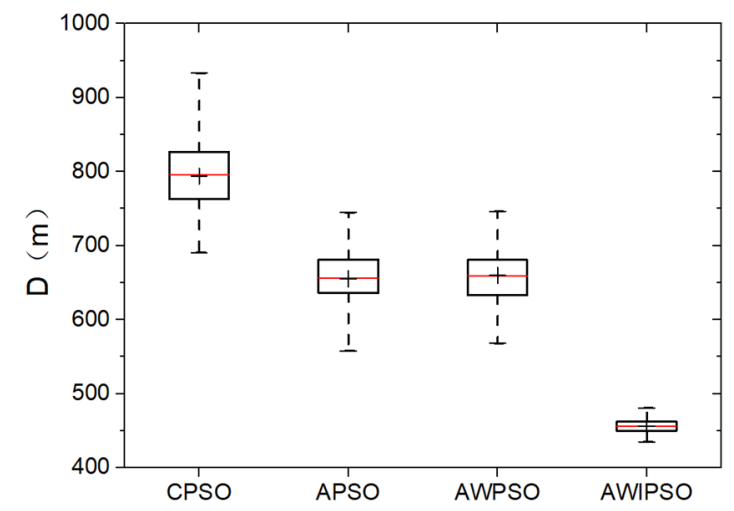

(d)

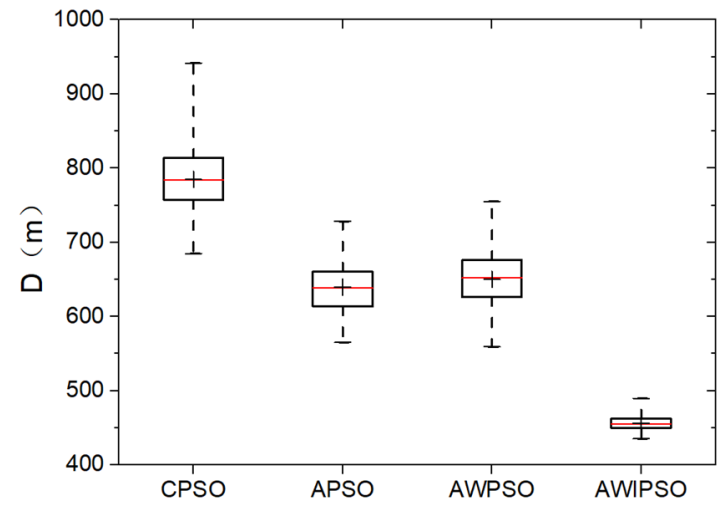

(e)

Figure 3. Solution distribution of each algorithm with five population sizes: (a) $R=300$; (b) $R=400$; (c) $R=500 ;$ (d) $R=600 ;(\mathbf{e}) R=700$. 
Table 3. Statistical results of optimal path distance in 100 runs with five swarm sizes.

\begin{tabular}{cccccc}
\hline $\boldsymbol{R}$ & Algorithm & Worst $(\mathbf{m})$ & Best $(\mathbf{m})$ & Mean $(\mathbf{m})$ & Std. Dev. $(\mathbf{m})$ \\
\hline \multirow{4}{*}{300} & CPSO & 974.27 & 776.77 & 872.24 & 43.50 \\
& APSO & 781.48 & 601.64 & 696.70 & 40.75 \\
& AWPSO & 829.51 & 583.85 & 700.67 & 39.90 \\
& AWIPSO & 487.43 & 434.33 & 457.03 & 9.85 \\
\hline \multirow{4}{*}{400} & CPSO & 992.82 & 699.91 & 849.28 & 51.74 \\
& APSO & 770.40 & 566.11 & 682.41 & 37.41 \\
& AWPSO & 792.31 & 568.42 & 676.16 & 41.31 \\
& AWIPSO & 495.28 & 434.84 & 456.84 & 10.69 \\
\multirow{5}{*}{500} & CPSO & 930.74 & 719.46 & 825.04 & 40.90 \\
& APSO & 765.91 & 582.15 & 663.66 & 35.23 \\
& AWPSO & 755.14 & 584.22 & 666.19 & 37.57 \\
& AWIPSO & 485.47 & 434.60 & 457.57 & 9.75 \\
\hline \multirow{4}{*}{600} & CPSO & 933.20 & 690.43 & 793.78 & 49.21 \\
& APSO & 744.87 & 557.78 & 655.20 & 32.53 \\
& AWPSO & 746.03 & 568.09 & 659.74 & 38.71 \\
& AWIPSO & 480.44 & 434.9 & 456.19 & 9.11 \\
\hline \multirow{5}{*}{700} & CPSO & 941.57 & 684.87 & 784.95 & 42.51 \\
& APSO & 728.26 & 564.87 & 639.80 & 34.03 \\
& AWPSO & 755.14 & 559.05 & 650.16 & 37.26 \\
& AWIPSO & 489.62 & 435.14 & 456.05 & 9.23 \\
\hline
\end{tabular}

Std. Dev. is the abbreviation for standard deviation.

In general, the effects of the swarm size on algorithm performance are that the overall optimal distance can be further reduced for each algorithm with the increase of swarm size. For instance, the average value of D for the CPSO is $785.0 \mathrm{~m}$ for $R=700$, which is $10 \%$ reduced compared with the case of $R=300$. For the AWIPSO, the average $\mathrm{D}$ is $456.1 \mathrm{~m}$ when $R=700$, and is only reduced by $0.2 \%$ with respect to the case of $R=300$. It could be concluded that the effects of swarm size on algorithm performance are not evident for the AWIPSO. Furthermore, although the robustness of every algorithm changes a little due to the swarm size, no regular tendency could be found. By contrast, the AWIPSO is always the most advantageous algorithm. Both the optimal path length and the algorithm robustness are almost unaffected by the swarm size. In the case of $R=700$, the mean distance and the standard deviation of AWIPSO are $456.1 \mathrm{~m}$ and $9.2 \mathrm{~m}$, which are $42.0 \%$ and $78.3 \%$ smaller than that of CPSO, respectively.

\subsubsection{Comparative Results of Computing Efficiency}

This section presents the evolution curves of five TSPLIB instances with different planned points (see in Section 3.1.1) to compare the computing efficiency of each algorithm. Two main criteria are selected for efficiency evaluation: the time consumption and the convergence speed. The former means the time consumption of completing the maximum number of iterations, and the latter refers to the critical number of iterations (mcri) at which the solution converges to the best value. Figure 4 shows the evolution history of optimal path distance $(D)$ against iteration $(m)$ for each algorithm within five hundred iterations. Meanwhile, all of the detailed information regarding computing efficiency for each algorithm is listed in Table 4. 




(a)

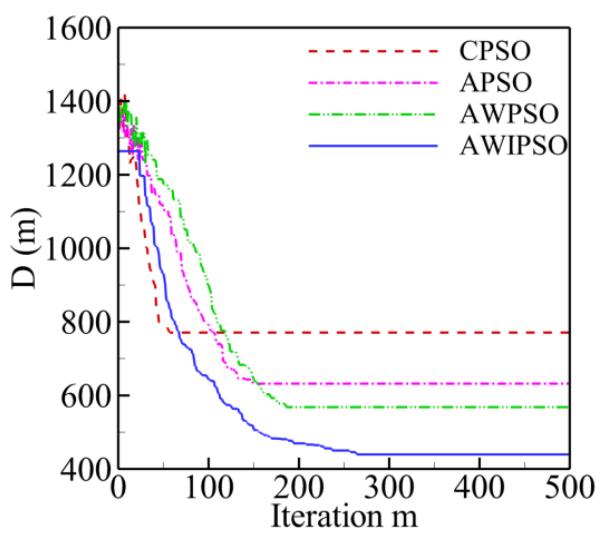

(c)

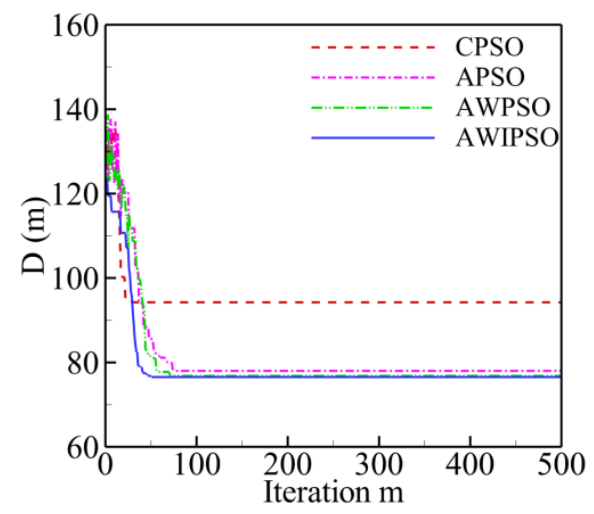

(b)

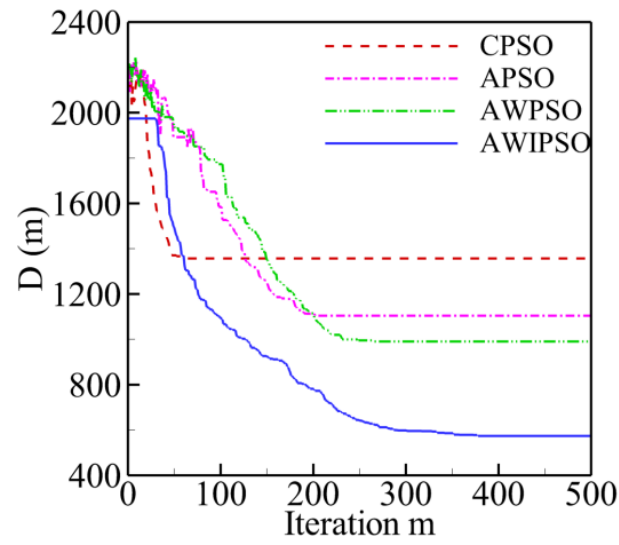

(d)

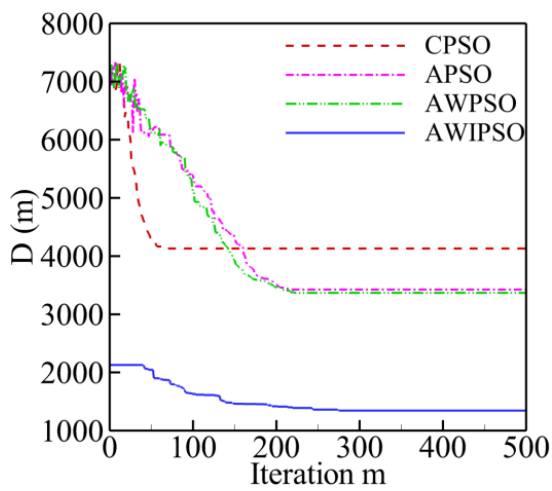

(e)

Figure 4. Evolution curves of optimal path distance against iterations for each algorithm: (a) $Q=14$; (b) $Q=22$; (c) $Q=51$; (d) $Q=76$; (e) $Q=99$. 
Table 4. Simulating results of computing efficiency for each algorithm.

\begin{tabular}{|c|c|c|c|c|}
\hline$Q$ & $M$ & Algorithm & $m_{c r i}$ & Time Cost \\
\hline \multirow{4}{*}{14} & \multirow{4}{*}{100} & CPSO & 57 & 0.3 \\
\hline & & APSO & 48 & 0.4 \\
\hline & & AWPSO & 32 & 0.3 \\
\hline & & AWIPSO & 28 & 1.3 \\
\hline \multirow{4}{*}{22} & \multirow{4}{*}{200} & CPSO & 32 & 0.4 \\
\hline & & APSO & 70 & 0.8 \\
\hline & & AWPSO & 75 & 0.9 \\
\hline & & AWIPSO & 51 & 2.9 \\
\hline \multirow{4}{*}{51} & \multirow{4}{*}{1600} & CPSO & 57 & 1.5 \\
\hline & & APSO & 153 & 11.0 \\
\hline & & AWPSO & 186 & 4.2 \\
\hline & & AWIPSO & 264 & 13.7 \\
\hline \multirow{4}{*}{76} & \multirow{4}{*}{2000} & CPSO & 61 & 3.0 \\
\hline & & APSO & 202 & 8.3 \\
\hline & & AWPSO & 266 & 10.6 \\
\hline & & AWIPSO & 378 & 23.6 \\
\hline \multirow{4}{*}{99} & \multirow{4}{*}{2000} & CPSO & 67 & 5.0 \\
\hline & & APSO & 210 & 14.0 \\
\hline & & AWPSO & 222 & 14.1 \\
\hline & & AWIPSO & 275 & 33.7 \\
\hline
\end{tabular}

Generally, it can be observed that the evolution curve of optimal path distance for each algorithm declines sharply with the increase of iteration during the initial stage, then the declining trend becomes a little milder, and finally reaches to a horizontal level at a critical number (mcri). The development of the evolution curve and the value of global optimum distance are completely dependent on the number of planned points and the utilized algorithm. With the increase of planned point numbers $(Q)$, both the critical number and the optimal distance have an increasing tendency for each algorithm.

By contrast, the AWIPSO converges to the shortest path distance when compared with the other algorithms for five numbers of planned points considered in this section; this was described in Section 3.1.1. In addition, when $P$ is less than 22, the critical number for AWIPSO has no evident difference compared with the others. However, with the increase of $Q$, the largest number of iterations is needed by the AWIPSO for convergence. When $Q=76$, for instance, the $m_{c r i}$ of AWIPSO is 378, which is 6, 1.9 and 1.4 times larger than that of CPSO, APSO, AWPSO, respectively. The cause behind this may be that the condition with more planned points would increase the complexity of route, and has a stronger demand for the algorithm performance, especially in avoiding the premature convergence. To put it another way, the CPSO, the APSO and the AWPSO are likely to be trapped in the local optimum during the evolution process which results in a relatively smaller $m_{c r i}$, while the AWIPSO could maintain the precision of solution which needs more iterations before convergence. As to the computing time, it is evident that the AWIPSO spends 6.7, 2.4 and 2.4 times more time than the CPSO, the APSO and the AWPSO to complete the same number of iterations when $Q=99$. To reduce the path distance, it is necessary to extend the computation time cost to a certain degree.

Furthermore, Figure 5 presents the best trajectories of the five TSPLIB instances (burma14, ulysses22, eil51, eil76, rat99) using the AWIPSO. The abscissa and ordinate stand for the values of latitude and longitude, respectively. The start point is enclosed in the red rectangle, and the arrows represent the heading of the planned path. It can be observed that the trajectories become more complex in the path shape and distance as $Q$ increases. 


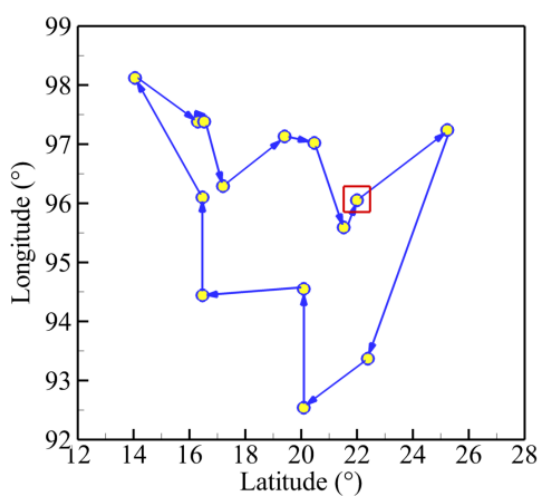

(a)

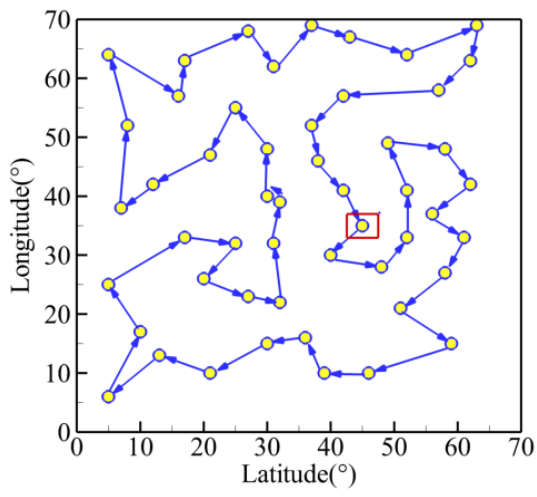

(c)

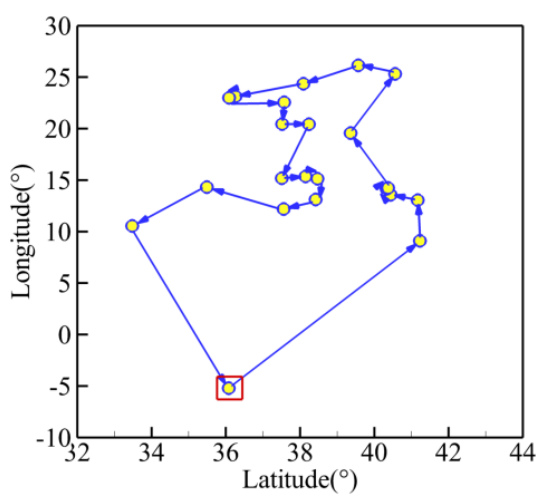

(b)

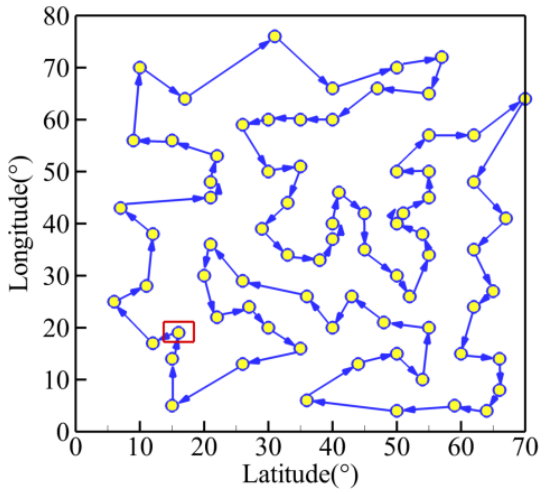

(d)

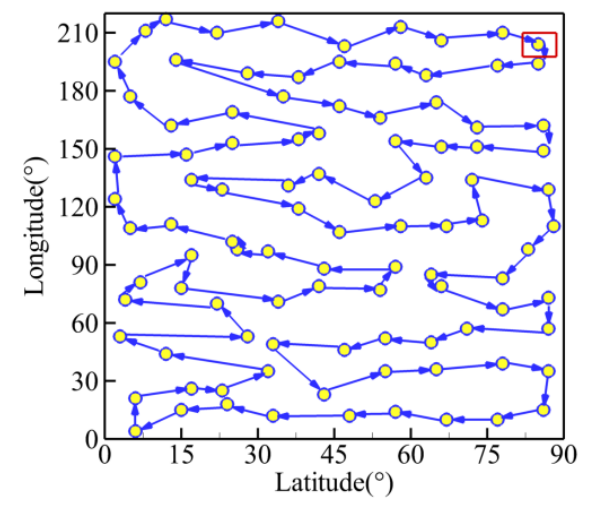

(e)

Figure 5. Best routes of five TSPLIB examples: (a) burma14; (b) ulysses22; (c) eil51; (d) eil76; (e) rat99.

\subsection{Multi-Sensor-Based Application to Unmanned Surface Vehicle}

Recently, USVs have been utilized worldwide in both civil and military fields, such as spot cruises in ocean ranching and multi-point water quality monitoring and sampling in vast water, due to the benefits of reduced casualty risk and increased mission efficiency [34-36]. A USV is typically equipped with a motion control unit, a sensor unit, a communications unit and an arming system. The motion control unit consists of the navigation positioning subsystem, the path planning subsystem and the trajectory tracking subsystem. As a core technology, the path planning is of great significance in realizing the autonomous navigation and control of the USV.

Generally, path planning can be reduced to the TSP if the prior environmental information is inaccessible and the collision-free restriction is not taken into account. Hence, the aforementioned algorithms can also be used to solve the USV path planning problem. In this section, the effectiveness of the improved algorithms is proved again by the application to the NGC system of a self-developed 
USV in real sea environment. As a preliminary study, the present work neglects the factors of wind, current and waves in the algorithms.

\subsubsection{Unmanned Surface Vehicle Model and Multi-Sensors}

Figure 6 presents a 3D model and physical photo of the USV model, which is self-designed and constructed by the Sea Wolf group of Qingdao University of Science and Technology. The length and width of the USV model are $1.8 \mathrm{~m}$ and $0.9 \mathrm{~m}$, respectively. It has five side bodies submerged in the water. Meanwhile, the electrical motors require a $48 \mathrm{~V} 45 \mathrm{~A}$ battery to provide power for the propeller.

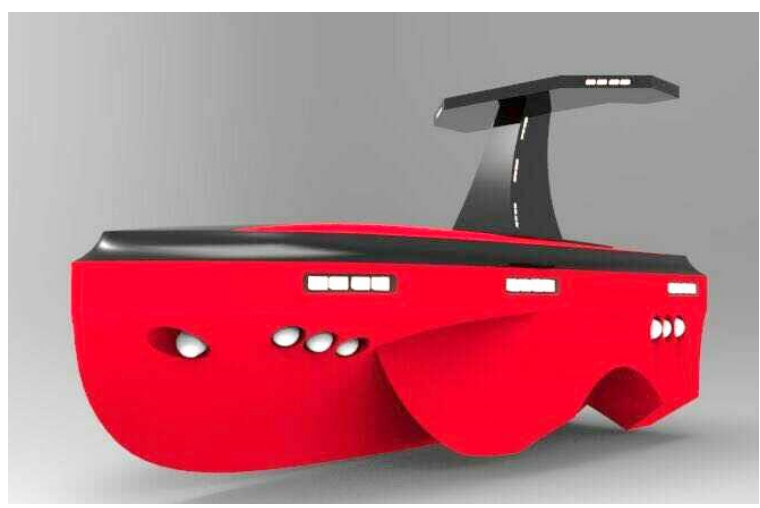

(a)



(b)

Figure 6. A self-developed unmanned surface vehicle: (a) 3D model; (b) USV in water.

Then, all the information is transferred to the path planning subsystem, where the PSOs are used to generate a desirable trajectory for the USV to follow. The autopilot employs a closed-loop controller to determine the heading and speed of the USV. In addition, a graphical user interface program is compiled based on the Spring model view controller framework to process and record all the data in a personal computer. The GPRS wireless network is established as the communication unit with the effective distance of $5 \mathrm{~km}$. The transmission speed is 1-100 Mbps [37].

The NGC system, as shown in Figure 7, involves three module subsystems: the navigation data processing subsystem, the path planning subsystem, and the autopilot subsystem. In addition, multi-sensors such as electronic compass and GPS are employed for gathering the navigation information of the direction of the bow and the location data of the USV. A WeatherStation ${ }^{\circledR}$ PB200 ultrasonic weather sensor, produced by AIRMAR ${ }^{\circledR}$ Technology Corporation, is used to collect the real-time, site-specific weather and location information. The navigation data are acquired by a navigation data acquisition system in real-time, along with the ship's log and the status information.

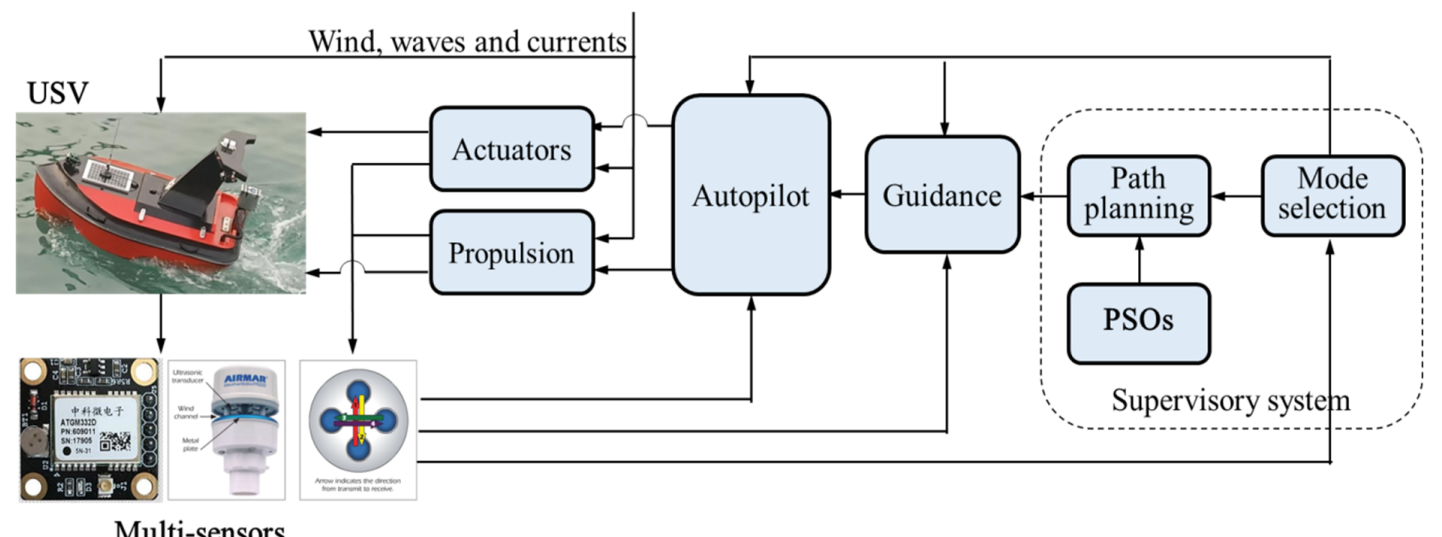

Figure 7. Navigation, guidance and control system of USV. 


\subsubsection{Application Tests in Real Maritime Environment}

This section applies the four aforementioned PSO methods to the NGC system of a USV model in real sea environment near the Qingdao Olympic Sailing Center in Fushan Bay. Two working conditions are used with different numbers of planned points: $Q=35$ and $Q=45$. The condition of $Q=35$ has the start point of $\left(\mathrm{N} 36^{\circ} 03^{\prime} 45.71^{\prime \prime}, \mathrm{E} 120^{\circ} 25^{\prime} 57.18^{\prime \prime}\right)$ in latitude and longitude, and the condition of $Q=45$ starts from the point of $\left(\mathrm{N} 36^{\circ} 03^{\prime} 45.78^{\prime \prime}, \mathrm{E} 120^{\circ} 25^{\prime} 56.66^{\prime \prime}\right)$. The location coordinates of other planned points refer to Tables A1 and A2. Then, comparative studies are conducted to assess the effectiveness of path planning for each algorithm. The swarm size $(R)$ is set as 500 . The maximum numbers of iterations $(M)$ are 350 and 450, respectively, which are dependent on the numbers of planned points.

Figures 8 and 9 present the optimal trajectory of each algorithm under each working condition with the detailed information listed in Table 5. When $Q=35$ in Figure 8, it is clear that the CPSO provides the worst route with serious level of path-crossing phenomenon, as marked in black circles, when compared with the other algorithms. This would be the reason the longest route distance is generated by the CPSO under the same condition. By using the three optimization strategies, it is possible to remove the self-crossing in the path to different degrees. Moreover, the AWIPSO performs best, with the shortest path of $1229.88 \mathrm{~m}$ and a relatively lower $m_{c r i}$ of 99 . Using pair-wise comparison, it is discovered that the path length has been optimized by $21.4 \%, 14.7 \%$, and $5.6 \%$ for strategies of adaptively controlled acceleration coefficients, linearly descending inertial weight, and random grouping inversion, respectively.

When $Q=45$, it could be found that the trajectories generated by the CPSO, APSO, and AWPSO have different levels of self-crossing in Figure $9 \mathrm{a}-\mathrm{c}$; this results in the evident increase of path length. However, at the same time, the advantages of the AWIPSO reflect more obviously in avoiding the intersection of route effectively and simplifying the path shape, especially when more planned points are considered. The optimal path length generated by the AWIPSO is $1380.84 \mathrm{~m}$, which is $48.0 \%, 38.9 \%$, and $27.5 \%$ shorter than that of the CPSO, APSO, and AWPSO, respectively. Pair-wise comparison indicates that the optimization with three rates of $14.8 \%, 15.7 \%$, and $27.5 \%$ were made by the respective effect of adaptively controlled acceleration coefficients, linearly descending inertial weight, and random grouping inversion.

In addition, all the improved algorithms require more time for computation than the CPSO under the same maximum number of iterations. As mentioned in Section 3.1.3, it is necessary to extend the time-cost to a certain degree for the purposes of improving the precision of solution and avoiding being trapped into local optima.

Table 5. Simulation results of each algorithm with two numbers of planned points.

\begin{tabular}{cccccc}
\hline $\boldsymbol{Q}$ & $\boldsymbol{M}$ & Algorithm & $\boldsymbol{m}_{\boldsymbol{c r i}}$ & Time Cost (s) & $\boldsymbol{D}(\mathbf{m})$ \\
\hline \multirow{4}{*}{35} & \multirow{3}{*}{350} & CPSO & 56 & 1.66 & 1942.50 \\
& & APSO & 147 & 2.97 & 1527.36 \\
& & AWPSO & 165 & 3.41 & 1303.14 \\
& & AWIPSO & 99 & 6.55 & 1229.88 \\
\hline \multirow{4}{*}{45} & \multirow{4}{*}{450} & CPSO & 60 & 2.45 & 2654.01 \\
& & APSO & 155 & 4.11 & 2261.07 \\
& & AWPSO & 217 & 5.17 & 1904.76 \\
& & AWIPSO & 118 & 10.64 & 1380.84 \\
\hline
\end{tabular}




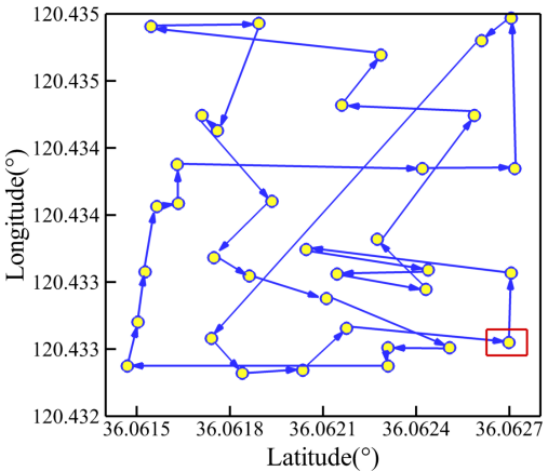

(a)

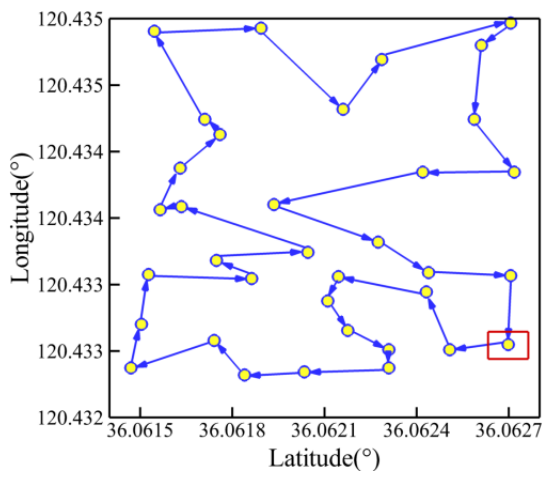

(c)

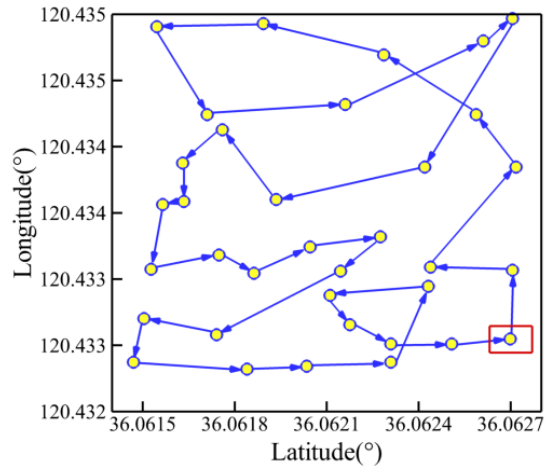

(b)

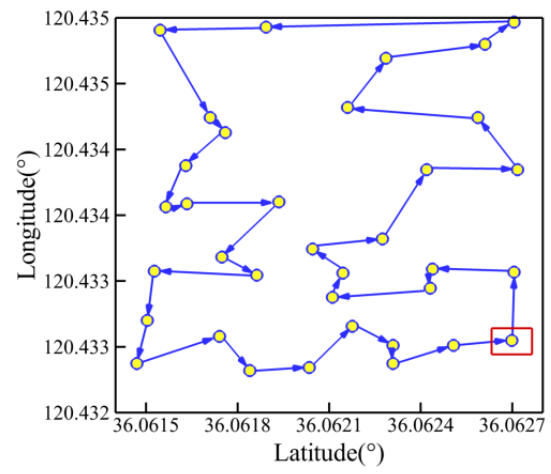

(d)

Figure 8. Trajectory planned by each algorithm for $Q=35$ : (a) CPSO; (b) APSO; (c) AWPSO; (d) AWIPSO.

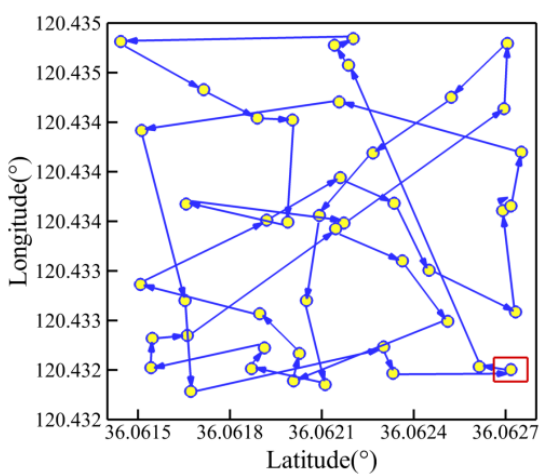

(a)

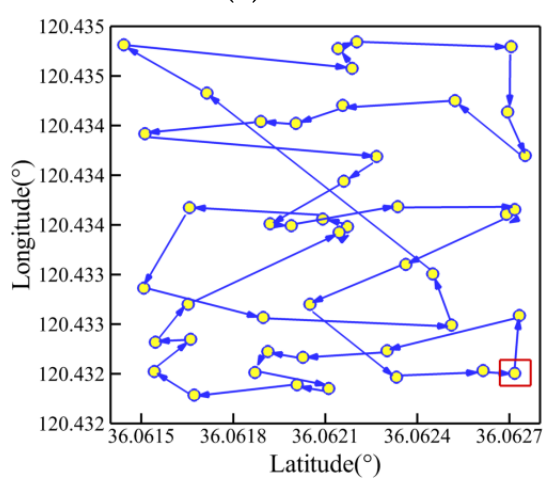

(c)

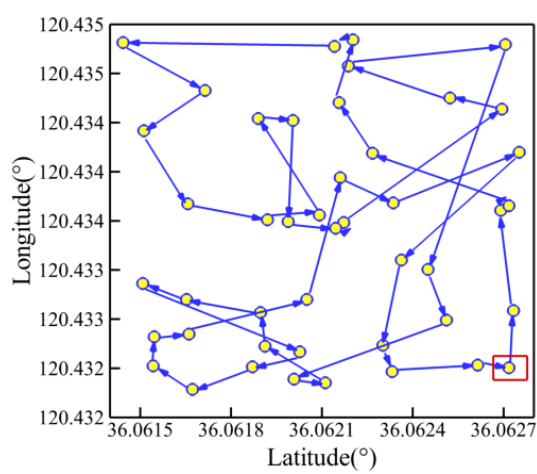

(b)

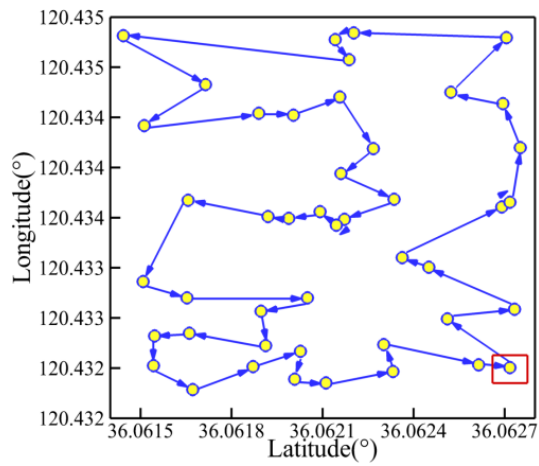

(d)

Figure 9. Trajectory planned by each algorithm for $Q=45$ : (a) CPSO; (b) APSO; (c) AWPSO; (d) AWIPSO. 


\section{Conclusions}

Multi-sensor fusion is an important issue for autonomous navigation of USVs. This work proposes three optimization strategies based on the conventional particle swarm optimization for real-time autonomous navigation of a USV in real maritime environment: the linearly descending inertia weight, the adaptively controlled acceleration coefficients, and the random grouping inversion. Monte Carlo simulations for five TSPLIB instances and application tests to an unmanned surface vehicle are conducted to reveal their respective or combinational advantages. Results can be concluded as follows:

(1) The adaptively controlled acceleration coefficients employ the influence of advantageous particles on the swarm, enhancing the capacity of the global search during early iterations and the local search during later stages. The strategy plays a substantial role in reducing the path length.

(2) The linearly descending inertia weight mainly helps to improve the algorithm robustness.

(3) The random grouping inversion optimizes the capacity of local search and maintains the population diversity; this can avoid premature convergence and keep the solution precision.

(4) The PSO combined with all the three strategies is superior to generate routes with the most satisfactory length and no self-crossing. However, more time consumption is required before global convergence.

(5) With more planned points, a more complex trajectory would be generated, would have a strong demand in terms of algorithm performance. However, the effects of swarm size on path planning for each algorithm are irregular, which could be neglected to some extent.

Since this work carries out the preliminary studies in optimizing the conventional PSO, more efforts are needed especially in further reducing the algorithm time cost. In the future, more comparative studies with different optimization algorithms for TSP will be conducted.

Author Contributions: J.X. and J.S. developed the idea and designed the exploration framework. S.L. developed the algorithms. Y.Z. performed the experiments. Y.C. drafted the manuscript.

Funding: This work is supported by the Key R \& D project of Shandong Province (Grant No. 2018YFJH0704), the Natural Science Foundation of China (Grant No.51609120), the Science and Technology Plan for Shandong University (Grant No. J16LB7), the Scientific Research Foundation of Chongqing Education Commission (Grant No. KJ1600509), and the Foundation and Frontier Projects of Chongqing Science and Technology Commission (Grant No. cstc2016jcyjA0561).

Conflicts of Interest: The authors declare no conflict of interest.

\section{Nomenclature}

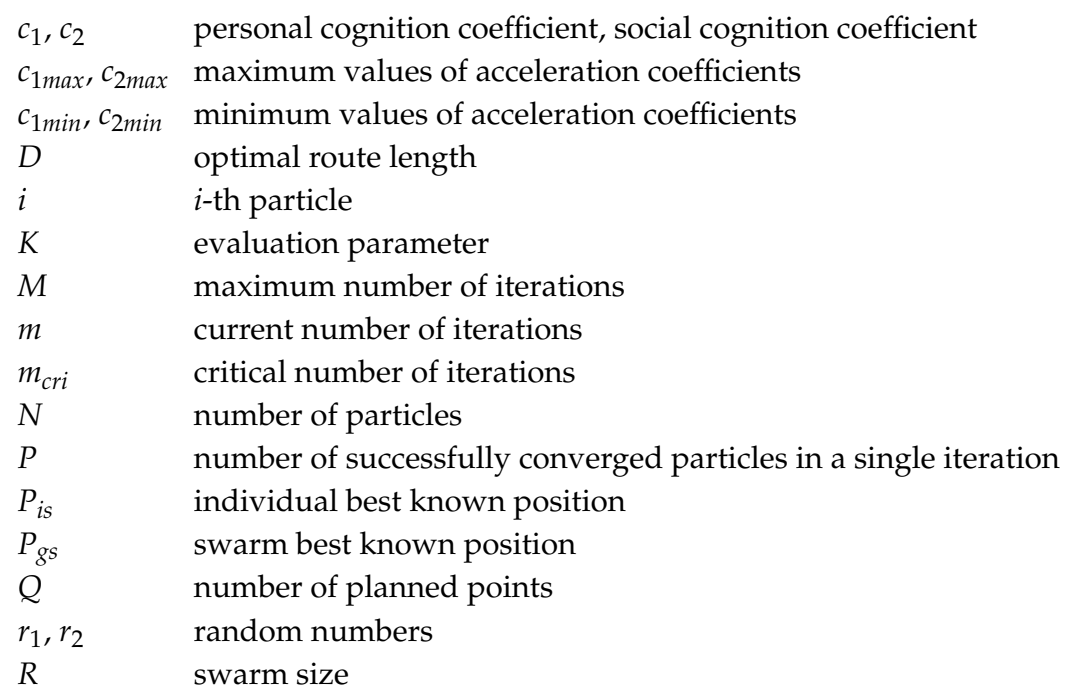




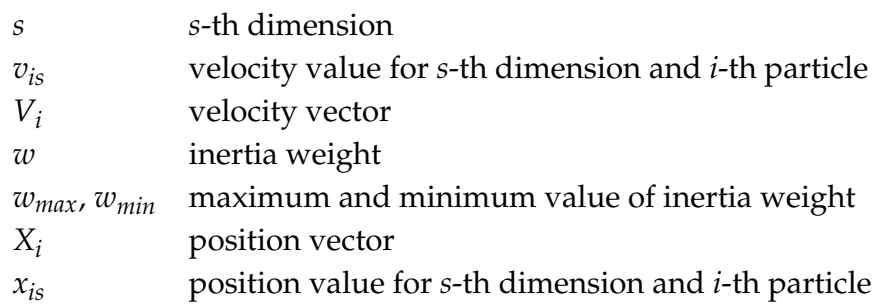

\section{Abbreviations}

ACO ant colony optimization

APSO particle swarm optimization with adaptively controlled acceleration coefficients

AWIPSO particle swarm optimization with adaptively controlled acceleration coefficients, linearly descending inertia weight, and random grouping inversion

AWPSO particle swarm optimization with adaptively controlled acceleration coefficients and linearly descending inertia weight

CPSO conventional particle swarm optimization

NGC navigation, guidance and control system

PSO particle swam optimization

TSP traveling salesman problem

USV unmanned surface vehicle

\section{Appendix A Location Coordinates of Planned Points}

Table A1. Location coordinates of 35 planned points.

\begin{tabular}{|c|c|c|c|c|c|}
\hline No. & Latitude & Longitude & No. & Latitude & Longitude \\
\hline 1 & N $36^{\circ} 03^{\prime} 45.71^{\prime \prime}$ & E $120^{\circ} 25^{\prime} 57.18^{\prime \prime}$ & 19 & N $36^{\circ} 03^{\prime} 41.88^{\prime \prime}$ & E $120^{\circ} 26^{\prime} 00.90^{\prime \prime}$ \\
\hline 2 & N $36^{\circ} 03^{\prime} 45.03^{\prime \prime}$ & E $120^{\circ} 25^{\prime} 57.03^{\prime \prime}$ & 20 & N $36^{\circ} 03^{\prime} 41.64^{\prime \prime}$ & E $120^{\circ} 26^{\prime} 00.83^{\prime \prime}$ \\
\hline 3 & N $36^{\circ} 03^{\prime} 44.31^{\prime \prime}$ & E $120^{\circ} 25^{\prime} 56.55^{\prime \prime}$ & 21 & N $36^{\circ} 03^{\prime} 45.32^{\prime \prime}$ & E $120^{\circ} 26^{\prime} 03.27^{\prime \prime}$ \\
\hline 4 & N $36^{\circ} 03^{\prime} 43.83^{\prime \prime}$ & E $120^{\circ} 25^{\prime} 57.55^{\prime \prime}$ & 22 & N $36^{\circ} 03^{\prime} 44.23^{\prime \prime}$ & E $120^{\circ} 26^{\prime} 04.89^{\prime \prime}$ \\
\hline 5 & N $36^{\circ} 03^{\prime} 43.32^{\prime \prime}$ & E $120^{\circ} 25^{\prime} 56.43^{\prime \prime}$ & 23 & N $36^{\circ} 03^{\prime} 42.81^{\prime \prime}$ & E $120^{\circ} 26^{\prime} 05.73^{\prime \prime}$ \\
\hline 6 & N $36^{\circ} 03^{\prime} 42.63^{\prime \prime}$ & E $120^{\circ} 25^{\prime} 56.34^{\prime \prime}$ & 24 & $\mathrm{~N} 36^{\circ} 03^{\prime} 42.16^{\prime \prime}$ & E $120^{\circ} 26^{\prime} 03.27^{\prime \prime}$ \\
\hline 7 & $\mathrm{~N} 36^{\circ} 03^{\prime} 42.26^{\prime \prime}$ & E $120^{\circ} 25^{\prime} 57.29^{\prime \prime}$ & 25 & $\mathrm{~N} 36^{\circ} 03^{\prime} 41.56^{\prime \prime}$ & E $120^{\circ} 26^{\prime} 05.67^{\prime \prime}$ \\
\hline 8 & N $36^{\circ} 03^{\prime} 41.29^{\prime \prime}$ & E $120^{\circ} 25^{\prime} 56.55^{\prime \prime}$ & 26 & N $36^{\circ} 03^{\prime} 43.36^{\prime \prime}$ & E $120^{\circ} 25^{\prime} 59.69^{\prime \prime}$ \\
\hline 9 & $\mathrm{~N} 36^{\circ} 03^{\prime} 45.74^{\prime \prime}$ & E $120^{\circ} 25^{\prime} 59.06^{\prime \prime}$ & 27 & $\mathrm{~N} 36^{\circ} 03^{\prime} 45.40^{\prime \prime}$ & E $120^{\circ} 26^{\prime} 05.28^{\prime \prime}$ \\
\hline 10 & N $36^{\circ} 03^{\prime} 44.76^{\prime \prime}$ & E $120^{\circ} 25^{\prime} 58.60^{\prime \prime}$ & 28 & $\mathrm{~N} 36^{\circ} 03^{\prime} 43.78^{\prime \prime}$ & E $120^{\circ} 26^{\prime} 03.55^{\prime \prime}$ \\
\hline 11 & $\mathrm{~N} 36^{\circ} 03^{\prime} 43.60^{\prime \prime}$ & E $120^{\circ} 25^{\prime} 58.34^{\prime \prime}$ & 29 & N $36^{\circ} 03^{\prime} 43.73^{\prime \prime}$ & E $120^{\circ} 25^{\prime} 59.02^{\prime \prime}$ \\
\hline 12 & N $36^{\circ} 03^{\prime} 42.71^{\prime \prime}$ & E $120^{\circ} 25^{\prime} 58.97^{\prime \prime}$ & 30 & N $36^{\circ} 03^{\prime} 42.30^{\prime \prime}$ & E $120^{\circ} 25^{\prime} 59.46^{\prime \prime}$ \\
\hline 13 & N $36^{\circ} 03^{\prime} 41.42^{\prime \prime}$ & E $120^{\circ} 25^{\prime} 57.73^{\prime \prime}$ & 31 & N $36^{\circ} 03^{\prime} 41.86^{\prime \prime}$ & E $120^{\circ} 26^{\prime} 01.96^{\prime \prime}$ \\
\hline 14 & $\mathrm{~N} 36^{\circ} 03^{\prime} 41.50^{\prime \prime}$ & E $120^{\circ} 25^{\prime} 59.07^{\prime \prime}$ & 32 & $\mathrm{~N} 36^{\circ} 03^{\prime} 45.74^{\prime \prime}$ & E $120^{\circ} 26^{\prime} 05.88^{\prime \prime}$ \\
\hline 15 & N $36^{\circ} 03^{\prime} 45.78^{\prime \prime}$ & E $120^{\circ} 26^{\prime} 01.85^{\prime \prime}$ & 33 & N $36^{\circ} 03^{\prime} 44.78^{\prime \prime}$ & E $120^{\circ} 25^{\prime} 59.13^{\prime \prime}$ \\
\hline 16 & $\mathrm{~N} 36^{\circ} 03^{\prime} 44.72^{\prime \prime}$ & E $120^{\circ} 26^{\prime} 01.85^{\prime \prime}$ & 34 & $\mathrm{~N} 36^{\circ} 03^{\prime} 42.34^{\prime \prime}$ & E $120^{\circ} 26^{\prime} 02.87^{\prime \prime}$ \\
\hline 17 & N $36^{\circ} 03^{\prime} 44.19^{\prime \prime}$ & E $120^{\circ} 25^{\prime} 59.94^{\prime \prime}$ & 35 & N $36^{\circ} 03^{\prime} 44.32^{\prime \prime}$ & E $120^{\circ} 25^{\prime} 57.03^{\prime \prime}$ \\
\hline 18 & N $36^{\circ} 03^{\prime} 42.97^{\prime \prime}$ & E $120^{\circ} 26^{\prime} 00.98^{\prime \prime}$ & & & \\
\hline
\end{tabular}

Table A2. Location coordinates of 45 planned points.

\begin{tabular}{|c|c|c|c|c|c|}
\hline No. & Latitude & Longitude & No. & Latitude & Longitude \\
\hline 1 & $\mathrm{~N} 36^{\circ} 03^{\prime} 45.78^{\prime \prime}$ & E $120^{\circ} 25^{\prime} 56.66^{\prime \prime}$ & 24 & $\mathrm{~N} 36^{\circ} 03^{\prime} 43.78^{\prime \prime}$ & E $120^{\circ} 26^{\prime} 02.24^{\prime \prime}$ \\
\hline 2 & $\mathrm{~N} 36^{\circ} 03^{\prime} 45.41^{\prime \prime}$ & E $120^{\circ} 25^{\prime} 56.73^{\prime \prime}$ & 25 & 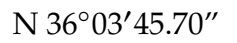 & E $120^{\circ} 26^{\prime} 04.23^{\prime \prime}$ \\
\hline 3 & $\mathrm{~N} 36^{\circ} 03^{\prime} 44.28^{\prime \prime}$ & E $120^{\circ} 25^{\prime} 57.31^{\prime \prime}$ & 26 & N $36^{\circ} 03^{\prime} 45.08^{\prime \prime}$ & E $120^{\circ} 26^{\prime} 04.55^{\prime \prime}$ \\
\hline 4 & $\mathrm{~N} 36^{\circ} 03^{\prime} 44.40^{\prime \prime}$ & E $120^{\circ} 25^{\prime} 56.55^{\prime \prime}$ & 27 & $\mathrm{~N} 36^{\circ} 03^{\prime} 42.80^{\prime \prime}$ & E $120^{\circ} 26^{\prime} 03.96^{\prime \prime}$ \\
\hline 5 & $\mathrm{~N} 36^{\circ} 03^{\prime} 43.60^{\prime \prime}$ & E $120^{\circ} 25^{\prime} 56.21^{\prime \prime}$ & 28 & N $36^{\circ} 03^{\prime} 42.17^{\prime \prime}$ & E $120^{\circ} 26^{\prime} 04.79^{\prime \prime}$ \\
\hline 6 & $\mathrm{~N} 36^{\circ} 03^{\prime} 43.23^{\prime \prime}$ & E $120^{\circ} 25^{\prime} 56.32^{\prime \prime}$ & 29 & N $36^{\circ} 03^{\prime} 45.74^{\prime \prime}$ & E $120^{\circ} 26^{\prime} 06.14^{\prime \prime}$ \\
\hline
\end{tabular}


Table A2. Cont.

\begin{tabular}{|c|c|c|c|c|c|}
\hline No. & Latitude & Longitude & No. & Latitude & Longitude \\
\hline 7 & $\mathrm{~N} 36^{\circ} 03^{\prime} 43.30^{\prime \prime}$ & E $120^{\circ} 25^{\prime} 57.12^{\prime \prime}$ & 30 & N $36^{\circ} 03^{\prime} 43.93^{\prime \prime}$ & E $120^{\circ} 26^{\prime} 06.27^{\prime \prime}$ \\
\hline 8 & $\mathrm{~N} 36^{\circ} 03^{\prime} 42.02^{\prime \prime}$ & E $120^{\circ} 25^{\prime} 56.03^{\prime \prime}$ & 31 & N $36^{\circ} 03^{\prime} 41.19^{\prime \prime}$ & E $120^{\circ} 26^{\prime} 06.18^{\prime \prime}$ \\
\hline 9 & $\mathrm{~N} 36^{\circ} 03^{\prime} 41.56^{\prime \prime}$ & E $120^{\circ} 25^{\prime} 57.55^{\prime \prime}$ & 32 & $\mathrm{~N} 36^{\circ} 03^{\prime} 43.72^{\prime \prime}$ & E $120^{\circ} 26^{\prime} 00.75^{\prime \prime}$ \\
\hline 10 & N $36^{\circ} 03^{\prime} 41.55^{\prime \prime}$ & E $120^{\circ} 25^{\prime} 56.71^{\prime \prime}$ & 33 & N $36^{\circ} 03^{\prime} 42.89^{\prime \prime}$ & E $120^{\circ} 25^{\prime} 57.28^{\prime \prime}$ \\
\hline 11 & $\mathrm{~N} 36^{\circ} 03^{\prime} 45.83^{\prime \prime}$ & E $120^{\circ} 25^{\prime} 58.33^{\prime \prime}$ & 34 & $\mathrm{~N} 36^{\circ} 03^{\prime} 44.16^{\prime \prime}$ & E $120^{\circ} 26^{\prime} 02.94^{\prime \prime}$ \\
\hline 12 & $\mathrm{~N} 36^{\circ} 03^{\prime} 45.04^{\prime \prime}$ & E $120^{\circ} 25^{\prime} 58.05^{\prime \prime}$ & 35 & N $36^{\circ} 03^{\prime} 42.73^{\prime \prime}$ & E $120^{\circ} 25^{\prime} 56.68^{\prime \prime}$ \\
\hline 13 & $\mathrm{~N} 36^{\circ} 03^{\prime} 43.38^{\prime \prime}$ & E $120^{\circ} 25^{\prime} 58.67^{\prime \prime}$ & 36 & $\mathrm{~N} 36^{\circ} 03^{\prime} 43.22^{\prime \prime}$ & E $120^{\circ} 26^{\prime} 03.89^{\prime \prime}$ \\
\hline 14 & $\mathrm{~N} 36^{\circ} 03^{\prime} 44.50^{\prime \prime}$ & E $120^{\circ} 25^{\prime} 59.82^{\prime \prime}$ & 37 & N $36^{\circ} 03^{\prime} 43.87^{\prime \prime}$ & E $120^{\circ} 26^{\prime} 05.49^{\prime \prime}$ \\
\hline 15 & $\mathrm{~N} 36^{\circ} 03^{\prime} 41.96^{\prime \prime}$ & E $120^{\circ} 25^{\prime} 58.65^{\prime \prime}$ & 38 & N $36^{\circ} 03^{\prime} 45.78^{\prime \prime}$ & E $120^{\circ} 26^{\prime} 01.41^{\prime \prime}$ \\
\hline 16 & $\mathrm{~N} 36^{\circ} 03^{\prime} 41.43^{\prime \prime}$ & E $120^{\circ} 25^{\prime} 59.13^{\prime \prime}$ & 39 & N $36^{\circ} 03^{\prime} 41.98^{\prime \prime}$ & E $120^{\circ} 25^{\prime} 57.65^{\prime \prime}$ \\
\hline 17 & N $36^{\circ} 03^{\prime} 45.69^{\prime \prime}$ & E $120^{\circ} 26^{\prime} 01.27^{\prime \prime}$ & 40 & N $36^{\circ} 03^{\prime} 43.77^{\prime \prime}$ & E $120^{\circ} 26^{\prime} 04.44^{\prime \prime}$ \\
\hline 18 & $\mathrm{~N} 36^{\circ} 03^{\prime} 44.41^{\prime \prime}$ & E $120^{\circ} 26^{\prime} 01.50^{\prime \prime}$ & 41 & $\mathrm{~N} 36^{\circ} 03^{\prime} 43.70^{\prime \prime}$ & E $120^{\circ} 26^{\prime} 06.07^{\prime \prime}$ \\
\hline 19 & $\mathrm{~N} 36^{\circ} 03^{\prime} 43.82^{\prime \prime}$ & E $120^{\circ} 26^{\prime} 00.91^{\prime \prime}$ & 42 & N $36^{\circ} 03^{\prime} 44.82^{\prime \prime}$ & E $120^{\circ} 25^{\prime} 59.54^{\prime \prime}$ \\
\hline 20 & N $36^{\circ} 03^{\prime} 43.53^{\prime \prime}$ & E $120^{\circ} 26^{\prime} 01.14^{\prime \prime}$ & 43 & N $36^{\circ} 03^{\prime} 41.45^{\prime \prime}$ & E $120^{\circ} 26^{\prime} 03.60^{\prime \prime}$ \\
\hline 21 & $\mathrm{~N} 36^{\circ} 03^{\prime} 43.15^{\prime \prime}$ & E $120^{\circ} 26^{\prime} 00.93^{\prime \prime}$ & 44 & $\mathrm{~N} 36^{\circ} 03^{\prime} 42.84^{\prime \prime}$ & E $120^{\circ} 25^{\prime} 58.28^{\prime \prime}$ \\
\hline 22 & $\mathrm{~N} 36^{\circ} 03^{\prime} 42.92^{\prime \prime}$ & E $120^{\circ} 26^{\prime} 01.00^{\prime \prime}$ & 45 & $\mathrm{~N} 36^{\circ} 03^{\prime} 45.91^{\prime \prime}$ & E $120^{\circ} 26^{\prime} 02.97^{\prime \prime}$ \\
\hline 23 & N $36^{\circ} 03^{\prime} 41.97^{\prime \prime}$ & E $120^{\circ} 26^{\prime} 01.45^{\prime \prime}$ & & & \\
\hline
\end{tabular}

\section{References}

1. Brown, H.C.; Jenkins, L.K.; Meadows, G.A.; Shuchman, R.A. BathyBoat: An Autonomous Surface Vessel for Stand-alone Survey and Underwater Vehicle Network Supervision. Mar. Technol. Soc. J. 2010, 44, $20-29$. [CrossRef]

2. Naeem, W.; Xu, T.; Sutton, R.; Tiano, A. The design of a navigation, guidance, and control system for an unmanned surface vehicle for environmental monitoring. Proc. Inst. Mech. Eng. Part. M: J. Eng. Marit. Environ. 2008, 222, 67-79. [CrossRef]

3. Bingham, B.; Kraus, N.; Howe, B.; Freitag, L.; Ball, K.; Koski, P.; Gallimore, E. Passive and active acoustics using an autonomous wave glider. J. Field Robot. 2012, 29, 911-923. [CrossRef]

4. Matos, A.; Silva, E.; Cruz, N.; Alves, J.C. Development of an unmanned vapsule for large-scale maritime search and rescue. In Proceedings of the 2013 OCEANS, San Diego, CA, USA, 23-27 September 2013; pp. 1-8.

5. Mou, X.; Wang, H. Wide-Baseline Stereo-Based Obstacle Mapping for Unmanned Surface Vehicles. Sensors 2018, 18, 1085. [CrossRef] [PubMed]

6. Liu, Z.; Zhang, Y.; Yu, X.; Yuan, C. Unmanned surface vehicles: An overview of developments and challenges. Annu. Rev. Control. 2016, 41,71-93. [CrossRef]

7. Garey, M.R.; Johnson, D.S. Computers and Intractability: A Guide to the Theory of NP-Completeness; W. H. Freeman and Company: San Francisco, CA, USA, 1979.

8. Holland, J.H. Genetic Algorithms and the Optimal Allocation of Trials. SIAM J. Comput. 1973, 2, 88-105. [CrossRef]

9. Gao, Y.; Wang, J.; Wu, W.; Sangaiah, A.K.; Lim, S.J. A Hybrid Method for Mobile Agent Moving Trajectory Scheduling using ACO and PSO in WSNs. Sensors 2019, 19, 575. [CrossRef]

10. Dahan, F.; EL Hindi, K.; Mathkour, H.; AlSalman, H. Dynamic Flying Ant Colony Optimization (DFACO) for Solving the Traveling Salesman Problem. Sensors 2019, 19, 1837. [CrossRef]

11. Li, X.L. A New Intelligent Optimization Method, Artificial Fish Swarm Algorithm; Zhejiang University: Hangzhou, China, 2003.

12. Karaboga, D. An Idea Based on Honey Bee Swarm for Numerical Optimization; Technical Report-TRKayseri; Erciyes University: Kayseri, Turkey, 2005.

13. Kennedy, J.; Eberhart, R.C. Particle Swarm Optimization. In Proceedings of the IEEE International Conference on Neural Networks, IEEE Service Center, Piscataway, NJ, USA, 27 November-1 December 1995; pp. 1942-1948.

14. Yaghini, M.; Khoshraftar, M.M.; Fallahi, M. A hybrid algorithm for artificial neural network training. Eng. Appl. Artif. Intell. 2013, 26, 293-301. [CrossRef] 
15. Xiong, W.; Zhuo, D.; Xie, Y.; Wang, X. Drawbead geometric parameters using an improved equivalent model and PSO-BP neural network. Proc. Inst. Mech. Eng. Part. L: J. Mater. Des. Appl. 2015, 230, 899-910.

16. Bounar, N.; Labdai, S.; Boulkroune, A. PSO-GSA based fuzzy sliding mode controller for DFIG-based wind turbine. ISA Trans. 2018, 85, 177-188. [CrossRef] [PubMed]

17. Shuang, B.; Chen, J.; Li, Z. Study on hybrid PS-ACO algorithm. Appl. Intell. 2009, 34, 64-73. [CrossRef]

18. Qiu, H.; Zhang, X. Hybrid particle swarm optimisation with k-centres method and dynamic velocity range setting for travelling salesman problems. Int. J. Bio-Inspired Comput. 2010, 2, 34.

19. Feng, H.M.; Liao, K.L. Hybrid evolutionary fuzzy learning scheme in the applications of traveling salesman problems. Inf. Sci. 2014, 270, 204-225. [CrossRef]

20. Mahi, M.; Baykan, O.K.; Kodaz, H. A new hybrid method based on Particle Swarm Optimization, Ant Colony Optimization and 3-Opt algorithms for Traveling Salesman Problem. Appl. Soft Comput. 2015, 30, 484-490. [CrossRef]

21. Deng, W.; Chen, R.; He, B.; Liu, Y.; Yin, L.; Guo, J. A novel two-stage hybrid swarm intelligence optimization algorithm and application. Soft Comput. 2012, 16, 1707-1722. [CrossRef]

22. Jiang, C.; Wan, L.; Sun, Y.; Li, Y. The Application of PSO-AFSA Method in Parameter Optimization for Underactuated Autonomous Underwater Vehicle Control. Math. Probl. Eng. 2017, 2017, 1-14. [CrossRef]

23. Zhang, Y.; Wu, L.; Wang, S. UCAV Path Planning by Fitness-Scaling Adaptive Chaotic Particle Swarm Optimization. Math. Probl. Eng. 2013, 2013, 1-9. [CrossRef]

24. Marinakis, Y.; Marinaki, M.; Migdalas, A. A multi-adaptive particle swarm optimization for the vehicle routing problem with time windows. Inf. Sci. 2019, 481, 311-329. [CrossRef]

25. Harrison, K.R.; Engelbrecht, A.P.; Ombuki-Berman, B.M. Optimal parameter regions and the time-dependence of control parameter values for the particle swarm optimization algorithm. Swarm Evol. Comput. 2018, 41, 20-35. [CrossRef]

26. Kenefic, R.J. Finding Good Dubins Tours for UAVs Using Particle Swarm Optimization. J. Aerosp. Comput. Inf. Commun. 2008, 5, 47-56. [CrossRef]

27. Masehian, E.; Sedighizadeh, D. A multi-objective PSO-based algorithm for robot path planning. In Proceedings of the 2010 IEEE International Conference on Industrial Technology, Vina del Mar, Chile, 14-17 March 2010.

28. Phung, M.D.; Quach, C.H.; Dinh, T.H.; Ha, Q. Enhanced discrete particle swarm optimization path planning for UAV vision-based surface inspection. Autom. Constr. 2017, 81, 25-33. [CrossRef]

29. Yan, Z.; Li, J.; Wu, Y.; Zhang, G. A Real-Time Path Planning Algorithm for AUV in Unknown Underwater Environment Based on Combining PSO and Waypoint Guidance. Sensors 2018, 19, 20. [CrossRef] [PubMed]

30. Shi, Y.; Eberhart, R.C. A Modified particle Swarm Optimizer. In Proceedings of the IEEE International Conference of Evolutionary Computation, Anchorage, AK, USA, 4-9 May 1998.

31. Marinakis, Y.; Marinaki, M. A Hybrid Multi-Swarm Particle Swarm Optimization algorithm for the Probabilistic Traveling Salesman Problem. Comput. Oper. Res. 2010, 37, 432-442. [CrossRef]

32. Ratnaweera, A.; Halgamuge, S.K.; Watson, H.C. Self-organizing hierarchical particle swarm optimizer with time-varying acceleration coefficients. IEEE Trans. Evol. Comput. 2004, 8, 240-255. [CrossRef]

33. Spear, M.E. Charting Statistics; McGraw-Hill: New York, NY, USA, 1952.

34. Li, C.; Jiang, J.; Duan, F.; Liu, W.; Wang, X.; Bu, L.; Sun, Z.; Yang, G. Modeling and Experimental Testing of an Unmanned Surface Vehicle with Rudderless Double Thrusters. Sensors 2019, 19, 2051. [CrossRef]

35. Jorge, V.A.M.; Granada, R.; Maidana, R.G.; Jurak, D.A.; Heck, G.; Negreiros, A.P.F.; Dos Santos, D.H.; Gonçalves, L.M.G.; Amory, A.M. A Survey on Unmanned Surface Vehicles for Disaster Robotics: Main Challenges and Directions. Sensors 2019, 19, 702. [CrossRef]

36. Jin, J.; Zhang, J.; Liu, D. Design and Verification of Heading and Velocity Coupled Nonlinear Controller for Unmanned Surface Vehicle. Sensors 2018, 18, 3427. [CrossRef]

37. Xin, J.; Zhong, J.; Yang, F.; Cui, Y.; Sheng, J. An Improved Genetic Algorithm for Path-Planning of Unmanned Surface Vehicle. Sensors 2019, 19, 2640. [CrossRef]

(C) 2019 by the authors. Licensee MDPI, Basel, Switzerland. This article is an open access article distributed under the terms and conditions of the Creative Commons Attribution (CC BY) license (http://creativecommons.org/licenses/by/4.0/). 